\title{
Analysis of Experimental Ice Accretion Data and Assessment of a Thermodynamic Model During Ice Crystal Icing
}

\author{
Tadas P. Bartkus and Jen-Ching Tsao \\ Ohio Aerospace Institute \\ Peter M. Struk \\ NASA John Glenn Research Center
}

\begin{abstract}
This paper analyzes ice crystal icing accretion data and evaluates a thermodynamic ice crystal icing model, which has been previously presented, to describe the possible mechanisms of icing within the core of a turbofan jet engine. The model functions between two distinct ice accretions based on a surface energy balance: freeze-dominated icing and melt-dominated icing. Freeze-dominated icing occurs when liquid water (from melted ice crystals) freezes and accretes on a surface along with the existing ice of the impinging water and ice mass. This freeze-dominated icing is characterized as having strong adhesion to the surface. The amount of ice accretion is partially dictated by a freeze fraction, which is the fraction of impinging liquid water that freezes. Melt-dominated icing occurs as unmelted ice on a surface accumulates. This melt-dominated icing is characterized by weakly bonded surface adhesion. The amount of ice accumulation is partially dictated by a melt fraction, which is the fraction of impinging ice crystals that melts. Experimentally observed ice growth rates suggest that only a small fraction of the impinging ice remains on the surface, implying a mass loss mechanism such as splash, runback, bounce, or erosion. The fraction of mass loss must be determined in conjunction with the fraction of freezing liquid water or fraction of melting ice on an icing surface for a given ice growth rate. This mass loss parameter, however, along with the freeze fraction and melt fraction, are the only experimental parameters that are currently not measured directly. Using icing growth rates from ice crystal icing experiments, a methodology that has been previously proposed is used to determine these unknown parameters. This work takes ice accretion data from tests conducted by the National Aeronautics and Space Administration (NASA) at the Glenn Research Center in 2018 that examined the fundamental physics of ice crystal icing. This paper continues evaluation of the thermodynamic model from a previous effort, with additions to the model that account for sub-freezing temperatures that have been observed at the leading edge of the airfoil during icing. The predicted temperatures were generally in good agreement with measured temperatures. Other key findings include the total wet-bulb temperature being a good first order indicator of whether icing is freeze-dominated (sub-freezing values) or melt-dominated (above freezing). Maximum sticking efficiency values, the fraction of impinging mass that adheres to a surface, was calculated to be about 0.2 , and retained this maximum value for a range of melt ratios $(0.3$ to 0.65 and possibly higher), which is defined as the ratio of liquid water content to total water content. Higher air velocities reduced the maximum sticking efficiency and shifted the icing regime to higher melt ratio values. Finally, the leading edge ice accretion angle was found to be related to ice growth (lower growth rates for smaller angles) and melt ratio (smaller melt ratios resulted in smaller angles, likely due to erosion effects).
\end{abstract}

\section{Introduction}

Since the 1990s, there have been numerous reports of turbofan engine power-loss or damage events that have been attributed to the ingestion of ice crystals. These events have been observed at altitudes at or above the upper limit at which water droplets can naturally exist as liquid. These events typically have occurred in deep convective updraft systems and have included engine stall, rollback, flameout, and engine component damage. Mason et al. [1] hypothesized that ice crystals ingested into the engine begin to undergo partial melting within the compressor system and then, as a mixed-phase water mass, accrete on surfaces within the engine core.

This threat of engine icing has spawned a substantial research effort in understanding the fundamental physics of ice crystal icing. To better understand the physical mechanisms of ice crystal icing, experiments have been conducted at the National Aeronautics and Space Administration (NASA) Glenn Research Center. Experimental studies on the fundamentals of ice crystal icing physics were conducted at the NASA Propulsion Systems Laboratory (PSL) in 2016 [2] and 2018 [3]. Other fundamental physics studies conducted elsewhere [4-12] have investigated altitude scaling [8], mixed-phase sticking efficiency [9], particle size effects $[10,11]$, and accretion angle effects [12] related to ice crystal icing.

In 2013, Currie et al. [8] of the National Research Council of Canada conducted a series of ice crystal accretion tests in development of scaling laws. Accretions were conducted on an axis-symmetric hemisphere ( $44.5 \mathrm{~mm}$ diameter) attached to a conical afterbody. Tests were conducted at air speeds of Mach $=0.25$, at absolute pressures of $34.5 \mathrm{kPa}$ and $69 \mathrm{kPa}$, and warmer than freezing temperatures, where the wet-bulb temperature ranged from approximately $0{ }^{\circ} \mathrm{C}$ to $6{ }^{\circ} \mathrm{C}$. The cloud median volumetric diameter, $M V D$, was measured to be $57 \mu \mathrm{m}$ [13]. Currie reported ice accretions that reached a steady-state size during a continuous exposure to a mixed-phase icing cloud. The steady-state ice shape was hypothesized to be a balance between accretion and erosion. Currie developed a semi-empirical model of the ice accretions that introduced a concept called sticking efficiency. This sticking efficiency, $\eta_{\text {stick }}$, was defined as the fraction of an impinging mixed-phase water mass flux that was retained on the surface. The model treated the accretion process as a strictly physical sticking phenomenon, ignoring heat transfer, phase change, and runback. Currie began to quantify an icing severity chart that identifies regions of maximum sticking efficiency with respect to the impinging cloud melt ratio, $\eta_{M R}$. The melt ratio is defined as the ratio of liquid water content to the total water content of the impinging cloud. For the conditions run, Currie reported maximum sticking efficiency in the melt ratio range of $0.10-0.25$ where the sticking efficiency ranged from 0.27 to 0.40 at the stagnation point, depending on the total water 
content of the impinging cloud. Sticking efficiency dropped off significantly at $\eta_{M R}$ values smaller and greater than the mentioned range, creating an icing severity plateau.

In 2014, Currie et al. [9] expanded the research efforts of ice crystal icing by running ice accretion test on three different airfoil geometries. The airfoils included the aforementioned axis-symmetric hemisphere, a crowned cylinder, and an axis-symmetric cone, where all three forebodies had a $44.5 \mathrm{~mm}$ diameter. Tests were conducted at flow speeds of Mach 0.25 and 0.40 and absolute pressures of $34.5 \mathrm{kPa}$ and $69 \mathrm{kPa}$, with cloud $M V D$ of $57 \mu \mathrm{m}$ [13]. Variations existed between different airfoil geometries, however, sticking efficiency was greatest in the melt ratio range of $0.1-0.2$ and reached stagnation point $\eta_{\text {stick }}$ values around $0.4-0.5$. Abrupt decreases in $\eta_{\text {stick }}$ value were again reported outside of the $0.1-0.2$ melt ratio range, creating an icing severity plateau. Currie reported that increased Mach number decreased the icing severity map, by creating a narrower icing severity plateau. Some of Currie's data suggests that at the higher Mach number, the height of the plateau is shallower too (possibly, according to Currie). Sticking efficiency decreased at oblique particle impingement angles (away from the stagnation point). Currie also reported that a steady-state ice shape was reached for all tests except for the highest total water content and slowest Mach number cases, where ice growth did not reach a limit. This is due to the sticking efficiency remaining non-zero at all oblique impingement angles. No significant effects due to pressure or total water content on sticking efficiency were found.

The French National Aerospace Center, ONERA, has made significant efforts to better understand ice crystal icing. They have developed a numerical icing tool, IGLOO2D, to address concerns raised by mixed phase icing. $[12,14]$. The accretion model, based on the extension of the Messinger model [15] that accounts for the presence of ice crystals among the impinging cloud particles, was evaluated against results from comprehensive icing wind tunnel tests conducted by the French agency. Accretion tests were conducted by Baumert et al. [12] utilizing a NACA 0012 airfoil and a cylindrical airfoil. The cylindrical airfoil had a diameter of $60 \mathrm{~mm}$, which corresponded to the maximum thickness of the NACA 0012 airfoil ( $500 \mathrm{~mm}$ chord length). Tests were conducted with an air velocity of $40 \mathrm{~m} / \mathrm{s}(\mathrm{Mach}=0.12)$, and cloud $M V D$ of $80 \mu \mathrm{m}$. Baumert was able to independently control air temperature and melt ratio. The paper reported several key findings. With respect to sticking efficiency and the icing severity map, Baumert reported wide icing severity plateaus for both airfoils, where $\eta_{M R}$ ranged from about 0.2 to 0.6 , with $\eta_{\text {stick }}$ values between 0.3 and 0.4 . Accretion tests with the cylindrical airfoil extended the range to $\eta_{M R}=1$, at wet-bulb temperatures of $-5^{\circ} \mathrm{C}$ and $-15^{\circ} \mathrm{C}$, where icing transitioned to supercooled liquid ice accretion. As reported by Baumert, at mixed phase conditions below the freezing point, no right end of the icing severity map exists. Baumert reported that $\eta_{\text {stick }}$ decreases with decreasing wet-bulb temperature, but is independent of total water content. Baumert observed time dependent accretion rates, which can be attributed to the leading edge ice accretion angle, $\varphi$. Investigating the accretion angle, Baumert reported lower $\eta_{\text {stick }}$ values at lower $\varphi$ values. This can be attributed to a reduction in collection efficiency around the stagnation point with narrower angles, and not benefitting from re-impingement after particle bounce/break-up that a wider angle ice accretion would experience. Finally, Baumert reported reduced $\varphi$ values at lower $\eta_{M R}$ values, likely due to erosion effects of the more glaciated cloud.

In 2014, Tsao et al. [16] proposed a thermodynamic model to describe the possible mechanisms for ice crystal icing on surfaces within the core of a jet engine. This thermodynamic model included factors not considered in work by Currie et al. $[8,9]$. The work by Tsao stated that there are two distinct types of ice accretions based on an overall energy balance at the accretion site. The first type is freeze-dominated icing, which occurs when liquid in a mixed-phase cloud freezes onto a surface along with ice present in the cloud. This freeze-dominated icing is characterized as having strong adhesion to the surface. The amount of ice accretion is partially dictated by a freeze fraction, $n_{0}$, which is the fraction of impinging liquid water that freezes. Melt-dominated icing occurs as unmelted ice on a surface accumulates. This melt-dominated icing is characterized by weakly bonded surface adhesion. The amount of ice accumulation is partially dictated by a melt fraction, $m_{0}$, which is the fraction of impinging ice crystals that melts. To determine the mass fraction values of $n_{0}$ or $m_{0}$, a mass loss parameter, $n_{\text {loss }}$, must be determined. This mass loss fraction, along with the freeze fraction or melt fraction, are the only parameters that are currently not measured directly.

Using reported icing growth rates from published ice crystal icing experiments, a methodology was proposed by Bartkus et al. [17] to determine these unknown parameters. The paper built on the previously proposed model by Tsao et al. [16] by adding a transient conduction term between the airfoil and ice accretion to explain ice growth behavior at the onset of experimental tests that was observed to be different from steady-state ice growth that occurred later in the test run. Several key findings were reported in the paper by Bartkus et al. The work suggested that mass loss fractions can exceed $n_{\text {loss }}=0.90$ for steady ice growth periods. The ice accretion rate and mass loss value for this steady ice growth period were measured and calculated for times between 120 and $180 \mathrm{~s}$ of mixed-phase ice cloud exposure on a NACA 0012 airfoil. Lower mass loss fraction values were calculated during the initial transient period. Due to the additional melt from conduction when using an initially warmer-than-freezing airfoil, a wet, sticky surface was likely the physical mechanism that allowed for more of the incoming cloud to be captured, reducing nloss. All initial transient periods in the experiments that were evaluated were determined to be melt-dominated icing, where transient measurements and calculations were taken within the first $20 \mathrm{~s}$ of mixed-phase ice cloud exposure. In addition, the paper noted that the total wet bulb temperature, $T w b_{0}$, which is the balance between convective and evaporative energy fluxes, was a good indicator for determining freeze-dominated or melt-dominated icing in which conduction was negligible. Generally, when $T w b_{0}$ is below freezing, freeze-dominated icing exists, and when $T w b_{0}$ is above freezing, melt-dominated icing exists. Another finding stated that for conditions that were sufficiently cold and freeze fraction values were $n_{0}=1$, then the icing surface temperature at the stagnation point could continue to decrease below $0{ }^{\circ} \mathrm{C}$ until it reached a thermodynamic equilibrium temperature. This ice temperature for these sufficiently cold cases was suggested to be the total wet-bulb temperature, but the paper did not provide any derivations or calculations to support this statement. A new addition to the model in this work addresses this icing surface temperature. Using ice growth rates, airfoil thermocouple measurements and test conditions from a companion paper by Struk et al. [3], the thermodynamic model will be further assessed, providing values to the unknown parameters of the melt-dominated or freeze-dominated ice accretions. These fundamental icing physics experiments were conducted at the NASA PSL icing wind tunnel in June 2018 using a NACA 0012 airfoil. These icing tests and this work are part of NASA's Advanced Air Transport Technology (AATT) Project roadmap to improve understanding of the ice growth physics and expand engine aero-thermodynamic modeling capability to predictively assess the onset and growth of ice in current and future engines during flight. 


\section{Objectives}

The main objective of this work is to evaluate the ice crystal icing thermodynamic model proposed by Tsao et al. [16] by solving for the unknown parameters of $n_{\text {loss }}$ and $n_{0}$ or $m_{0}$. These parameters will be determined by utilizing experimental ice accretion data from tests conducted by NASA in 2018 [3]. The model will be evaluated utilizing reported ice growth rates at the midspan of the NACA 0012 airfoil along with the measured conditions at the airfoil leading edge.

Additions were made to the model to determine the thermodynamic equilibrium icing surface temperature for tests where conditions were sufficiently cold to produce freeze fraction values of $n_{0}=1$. This new addition will be evaluated utilizing temperature data measured by a thermocouple located at the midspan and leading edge of the airfoil.

A final objective is to investigate sticking efficiency for the NASA 2018 experimental ice accretion data, and how $\eta_{\text {stick }}$ varies with the controlled parameters in the experiments, in particular, $\eta_{M R}$. In addition, this paper will examine the roll that the ice accretion angle, $\varphi$, played in the accretion process. These findings will be compared with previous work by Currie [8,9] and Baumert [12].

\section{Ice Crystal Icing Thermodynamic Model Description}

A thermodynamic model for ice crystal icing within the core of jet engines was proposed by Tsao et al. [16]. Bartkus et al. [17] built on the previously proposed model by Tsao by adding a transient conduction term to explain initial ice accretion growth rates that differed from ice accretion growth rates that occurred later in the ice cloud spray. Bartkus et al. [17] described the assumptions and surface energy balances that compose the model. They are repeated in the following sections for thoroughness. In this current study, a surface temperature energy balance is added to the thermodynamic model to address conditions where the icing surface temperature can become sub-freezing in temperature. In addition to the surface temperature energy balance, expressions for sticking efficiency, along with other mass loss factors are provided in the following sections.

\section{Model Assumptions}

The following assumptions are listed for assessing this thermodynamic model:

- Steady icing cloud flow and air flow relative to the accretion process.

- Accretion growth rates are taken at the stagnation point of an airfoil.

- All water mass comes from the impinging water or ice cloud, (i.e. no water flow from neighboring surface control volumes).

- All impinging water mass is at the freezing temperature of water $\left(0^{\circ} \mathrm{C}\right)$.

- Coefficients of heat and mass transfer, as initially measured on a non-iced airfoil surface, remain constant despite changing geometries as ice accretes on the airfoil.

\section{Surface Energy Balance Equations}

Tsao et al. [16] identified two distinct mechanisms for ice crystal icing growth: freeze-dominated icing and melt-dominated icing. The conservation of energy expressions for the icing surface for both mechanisms are taken from Tsao [16] and Bartkus [17] and are reproduced in the following sections.

\section{Freeze-Dominated Regime}

The governing energy conservation law at the icing surface for freezedominated icing is shown in Eq. (1). The sign convention assumes that the net energy transfer from the right-hand side of the equation is positive. Therefore, the left-hand side of the expression is also positive and represents the energy that is available for freezing, and is the latent heat of fusion surface energy for freezing, $q_{\text {freeze }}^{\prime \prime}$. In Eq. (1), $q_{\text {evap }}^{\prime \prime}$ is the evaporative heat transfer flux (heat transferred away from icing surface $=$ positive), $q_{\text {conv }}^{\prime \prime}$ is the convective heat transfer flux (heat to icing surface $=$ positive), $q_{\text {kinetic }}^{\prime \prime}$ is the kinetic energy transfer flux (energy into icing surface $=$ positive), and $q_{\text {cond }}^{\prime \prime}$ is the conductive heat transfer flux (heat to icing surface $=$ positive). These five surface balance energy terms are described in greater detail in the next paragraphs.

$$
q_{\text {freeze }}^{\prime \prime}=q_{\text {evap }}^{\prime \prime}-q_{\text {conv }}^{\prime \prime}-q_{\text {kinetic }}^{\prime \prime}-q_{\text {cond }}^{\prime \prime}
$$

The evaporative heat transfer flux at the icing surface is shown in Eq. (2). In the expression, $\dot{m}_{e}$ is the evaporative mass flux and $L_{v}$ is the latent heat of vaporization. It should be noted that ice on the surface will sublimate, and water will evaporate, so the value of $L_{v}$ will be dependent on the mixture (quality) of ice and liquid water. The evaporative mass flux term can be expressed in terms of an evaporative mass transfer coefficient, $h_{m}$, total temperature, $T_{0}$, static temperature, $T_{s}$, total pressure, $p_{0}$, static pressure, $p_{s}$, saturation vapor pressure of water in air, $p_{v, s}$, and the saturation vapor pressure of water at the icing surface, $p_{v, \text { surf }}$.

$$
q_{\text {evap }}^{\prime \prime}=\dot{m}_{e}^{\prime \prime} L_{v}=h_{m}\left(\frac{\frac{p_{v, \text { surf }}}{T_{S}}-\frac{p_{0}}{T_{0}} \cdot \frac{p_{v, s}}{p_{s}} \cdot R H_{s}}{\frac{1}{0.622} \cdot \frac{p_{0}}{T_{0}}-\frac{p_{v, \text { surf }}}{T_{S}}}\right) L_{v}
$$

The convective heat transfer flux at the icing surface is shown in Eq. (3). In the expression, $h_{c}$ is the convective heat transfer coefficient, $U$ is the air velocity, $C p_{\text {air }}$ is the specific heat capacity of air, and $T_{\text {surf }}$ is the icing surface temperature. The temperature recovery factor, the recovery of energy from static temperature as flow decelerates in the boundary layer, can be approximated to be unity (1.0) at the leading edge. For this reason, the sum of the first two terms within the parentheses of Eq. (3) is equivalent to the total air temperature.

$$
q_{\text {conv }}^{\prime \prime}=h_{c}\left(T_{s}+\frac{U^{2}}{2 C p_{\text {air }}}-T_{\text {surf }}\right)
$$

The kinetic energy transfer flux at the icing surface is shown in Eq. (4). In the expression, $\dot{m}_{\text {stick }}$ is the impinging mass flux that sticks (accretes), and $U$ is the velocity of the impinging mass (which is approximated to be equal to the air velocity). The composition of $\dot{m}_{\text {stick }}$ will be more fully described in the mass balance equation 
section. It should be noted that in this form, the equation neglects any kinetic energy transfer from the impinging mass flux that did not stick.

$$
q_{\text {kinetic }}^{\prime \prime}=\dot{m}_{s t i c k}^{\prime \prime} \cdot \frac{U^{2}}{2}
$$

The conduction heat transfer flux to the icing surface is shown in Eq. (5). In the expression, $k_{\text {wall }}$ is the thermal conductivity of the airfoil surface, and the $d T / d \hat{n}$ term refers to the change in temperature in the normal direction within the airfoil at the ice and airfoil interface $(\hat{n}=0)$. Heat transfer from the wall to the water/ice mix is positive in value, according the sign notation in Eq. (5).

$$
\left.q_{\text {cond }}^{\prime \prime}=k_{\text {wall }} \frac{d T}{d \hat{n}}\right]_{\text {wall }}
$$

It should be noted that the conduction term as presented in Eq. (5) is in steady-state form. Bartkus et al. [17] provided a derivation for a one dimensional (1D) transient conduction term in which an airfoil is initially at a different temperature than the surrounding icing cloud environment. Approximating the stagnation point of the airfoil as a 1D plane of thickness $L$, where the stagnation point temperature at $\hat{n}=0$ is fixed at the freezing temperature of $0{ }^{\circ} \mathrm{C}$, the internal wall at $\hat{n}=L$ as adiabatic, and the initial airfoil temperature as uniform, $T_{\text {wall }}$, the airfoil temperature at any time, $t$, and any location within the airfoil, $\hat{n}$, can be determined by the expression in Eq. (6). The infinite series solution in Eq. (6) is solved by using Separation of Variables with Fourier Series methods.

$$
T(\hat{n}, t)=\frac{4 T_{\text {wall }, i}}{\pi} \sum_{j=1}^{\infty} \frac{\sin \left[(2 j-1) \frac{\pi \hat{n}}{2 L} \cdot e^{-\left[\frac{(2 j-1)^{2} \pi^{2} k_{\text {wall }}}{4 L^{2} \rho_{\text {wall }} C p_{\text {wall }}}\right]}\right.}{2 j-1}
$$

In Eq. (6), $j$ represents the positive integers in the summation of the infinite series solution, $\rho_{\text {wall }}$ represents the airfoil density, and $C p_{\text {wall }}$ represent the airfoil specific heat. The thermal conductivity heat flux into the water/ice mass for any time, $t$, can be determined by solving for $T$ and calculating the spatial change in temperature at the ice and wall interface $(d T / d \hat{n}$ at $\hat{n}=0)$. Since the value of $d T / d \hat{n}$ changes with time, the thermal conductivity heat flux term is transient for the situation described in Eq. (6). The average conductive heat flux, $\bar{q}_{\text {cond }}^{\prime \prime}$, can be taken to approximate the conductive heat transferred between the airfoil and icing surface over a period of time

The latent heat of fusion surface energy for freezing, is shown in Eq. (7) in terms of freeze fraction, $n_{0}$. In the main expression, $\dot{m}_{\text {imp,liq }}^{\prime \prime}$ is the mass flux of liquid water, $L_{f}$ is the latent heat of fusion, and $n_{\text {loss }}$ is the fraction of ice mass lost due to bounce and erosion. The value of $\dot{m}_{\text {imp,liq }}$ can be expressed in terms of total water content (TWC), melt ratio, collection efficiency at the stagnation line $\left(\beta_{0}\right)$, and particle mass velocity.

$$
\begin{aligned}
q_{\text {freeze }}^{\prime \prime}=\dot{m}_{\text {imp }, \text { liq }}^{\prime \prime} \cdot\left(1-n_{\text {loss }}\right) \cdot n_{0} \cdot L_{f} \\
=\left(T W C \cdot \eta_{M R}\right) \cdot \beta_{0} \cdot U \cdot\left(1-n_{\text {loss }}\right) \cdot n_{0} \cdot L_{f}
\end{aligned}
$$

Freeze-dominated icing focuses on the fraction of liquid water that can freeze, $n_{0}$. Equations (1) and (7) can be combined and arranged to solve for $n_{0}$, and is shown in Eq. (8).

Page 4 of 17

$$
n_{0}=\frac{q_{\text {evap }}^{\prime \prime}-q_{\text {conv }}^{\prime \prime}-q_{\text {kinetic }}^{\prime \prime}-q_{\text {cond }}^{\prime \prime}}{\dot{m}_{\text {imp }, \text { liq }}^{\prime \prime} \cdot L_{f} \cdot\left(1-n_{\text {loss }}\right)}
$$

The individual energy fluxes in the numerator of Eq. (8) can be substituted with the respective expression from Eq. (2) through Eq. (5). It should be noted that liquid mass must initially be present for freeze-dominated icing to occur. In addition, it should be noted that the kinetic energy transfer flux is a function of $n_{\text {loss }}$ (it will be shown in the mass balance section that $\dot{m}_{\text {stick }}^{\prime \prime}$ is a function of $n_{\text {loss }}$ ) and therefore Eq. (8) contains two unknown parameters.

\section{Melt-Dominated Regime}

According to the sign convention in Eq. (1), the value of $q_{\text {freeze }}^{\prime \prime}$ will be positive in the freeze-dominated regime. If the sum of the terms on the right side of Eq. (1) is negative, then melt-dominated freezing occurs. This is explicitly expressed in Eq. (9), where $q_{\text {melt }}^{\prime \prime}$ is the latent heat of fusion surface energy for melting (the energy available for melting). According to the sign convention in Eq. (9), the value of $q_{m e l t}^{\prime \prime}$ is positive for melt-dominated icing.

$$
q_{\text {melt }}^{\prime \prime}=q_{\text {conv }}^{\prime \prime}+q_{\text {kinetic }}^{\prime \prime}+q_{\text {cond }}^{\prime \prime}-q_{\text {evap }}^{\prime \prime}
$$

The individual energy fluxes on the right-hand side of Eq. (9) are identical as expressed in the previous Freeze-Dominated Regime section. The value of $q_{m e l t}^{\prime \prime}$ can be expressed in terms of the impinging

ice mass flux rate, $\dot{m}_{\text {imp,ice }}^{\prime \prime}$, the latent heat of fusion, the ice mass melt fraction, $m_{0}$, and $n_{\text {loss }}$, and is shown in Eq. (10). The impinging ice mass flux can be expressed in terms of total water content, melt ratio, collection efficiency at the stagnation line, and particle mass velocity.

$$
\begin{array}{r}
q_{m e l t}^{\prime \prime}=\dot{m}_{\text {imp,ice }}^{\prime \prime} \cdot\left(1-n_{\text {loss }}\right) \cdot m_{0} \cdot L_{f} \\
=T W C \cdot\left(1-\eta_{M R}\right) \cdot \beta_{0} \cdot U \cdot\left(1-n_{\text {loss }}\right) \cdot m_{0} \cdot L_{f}
\end{array}
$$

Melt-dominated icing focuses on the fraction of ice that can melt, $m_{0}$. Equations (9) and (10) can be arranged for $m_{0}$, and is shown in Eq. (11).

$$
m_{0}=\frac{q_{\text {conv }}^{\prime \prime}+q_{\text {kinetic }}^{\prime \prime}+q_{\text {cond }}^{\prime \prime}-q_{\text {evap }}^{\prime \prime}}{\dot{m}_{\text {imp }, i c e}^{\prime \prime} \cdot L_{f} \cdot\left(1-n_{\text {loss }}\right)}
$$

It should be noted that ice mass must initially be present for melt-dominated icing to occur. Similar to the freeze mass fraction expression in Eq. (8), the kinetic energy transfer flux is a function of $n_{\text {loss }}$, and therefore Eq. (11) contains two unknown parameters.

\section{Mass Balance Equations Using Stagnation Icing Growth Rates}

All parameters in the expressions for the thermodynamic model can be measured experimentally except for $\beta_{0}, n_{\text {loss }}$, and $n_{0}$ in Eq. (8) and $m_{0}$ in Eq. (11). Values of $\beta_{0}$ are dependent on particle size, velocity, and airfoil geometry and can be approximated using simulation [18]. For this analysis, the collection efficiency value will be approximated to be unity, $\beta_{0}=1$ at the stagnation point. This leaves $n_{\text {loss }}$ as the only unknown for determining either $n_{0}$ or $m_{0}$. The values of $n_{\text {loss }}$, and $n_{0}$ or $m 0$, can be determined utilizing experimentally measured ice growth rates within mass balance equations. Equation (12) expresses the mass 
balance for freeze-dominated icing, utilizing the mass flux that accreted (i.e. stick). The ice growth rate, $\dot{t}_{\text {freeze }}$, is explicitly written to distinguish this as the freeze-dominated icing mass balance. Both $\dot{m}_{\text {imp,liq }}^{\prime \prime}$ and $\dot{m}_{\text {imp,ice }}^{\prime \prime}$ are broken down into more measurable components. Equation (13) expresses the mass balance for melt-dominated icing, where the ice growth rate, $\dot{t}_{\text {melt }}$, is explicitly written to distinguish this as the melt-dominated icing mass balance. The units of ice growth rates are in terms of distance over time.

$$
\begin{gathered}
\dot{m}_{\text {stick }}^{\prime \prime}=\dot{t}_{\text {freeze }} \cdot \rho_{\text {ice }}=\left(\dot{m}_{\text {imp }, \text { liq }}^{\prime \prime} \cdot n_{0}+\dot{m}_{\text {imp }, \text { ice }}^{\prime \prime}\right) \cdot\left(1-n_{\text {loss }}\right) \\
=T W C \cdot \beta_{0} \cdot U \cdot\left(\eta_{M R} \cdot n_{0}+\left(1-\eta_{M R}\right)\right) \cdot\left(1-n_{\text {loss }}\right) \\
\dot{m}_{\text {stick }}^{\prime \prime}=\dot{t}_{\text {melt }} \cdot \rho_{\text {ice }}=\left(\dot{m}_{\text {imp }, \text { ice }}^{\prime \prime} \cdot\left(1-m_{0}\right)\right) \cdot\left(1-n_{\text {loss }}\right) \\
=T W C \cdot \beta_{0} \cdot U \cdot\left(\left(1-\eta_{M R}\right)\left(1-m_{0}\right)\right) \cdot\left(1-n_{\text {loss }}\right)
\end{gathered}
$$

In Eq. (12) and (13), $\rho_{\text {ice }}$ is the density of accreted ice (approximated to be $916 \mathrm{~kg} / \mathrm{m}^{3}$ for this work). In Eq. (12), all of the ice mass along with water mass that freezes, after bounce and erosion losses, contributes to the ice growth. In Eq. (13), ice mass that has not melted, after losses, contributes to ice growth. For freeze-dominated icing, Eq. (8) and Eq. (12) are solved together, providing values for $n_{\text {loss }}$ and $n_{0}$. For melt-dominated icing, Eq. (11) and Eq. (13) are solved together, providing values for $n_{\text {loss }}$ and $m_{0}$. The unknown values cannot be solved for directly and must be determined by using an iterative solving method.

Currie $[8,9]$ proposed a straightforward mass balance that defined a sticking efficiency, $n_{\text {stick}}$, which was simply the fraction of the impinging mixed-phase mass flux that managed to stick to the surface. It is defined in Eq. (14)

$$
\eta_{\text {stick }}=\frac{\dot{t} \cdot \rho_{\text {ice }}}{\dot{m}_{\text {imp,total }}}
$$

Again, in Eq. (14), $\dot{m}_{i m p, t o t a l}^{\prime \prime}$ is the total impinging mass flux, which is also the sum of $\dot{m}_{i m p, l i q}^{\prime \prime}$ and $\dot{m}_{i m p, i c e}^{\prime \prime}$. Currie did not differentiate between freeze-dominated or melt-dominated icing, and therefore $\dot{t}$ is simply the general ice growth rate. Currie defined the complementary total mass loss fraction as well, $F_{\text {loss, total }}$, which is simply the fraction of impinging mass flux that did not stick, and is defined in Eq. (15).

$$
F_{\text {loss,total }}=1-\eta_{\text {stick }}
$$

It should be noted that $n_{\text {loss }}$ and $F_{\text {loss,total }}$ represent different losses. While $F_{\text {loss,total }}$ is the fraction of impinging total mass that is lost, $n_{\text {loss }}$ is the fraction of ice mass that is lost due to bounce and erosion. These two loss terms are related. Combining Eqs. (12), (14) and (15), then re-arranging for $n_{\text {loss }}$ provides the correlation for freeze-dominated icing, and is shown in Eq. (16).

$$
n_{\text {loss }}=1-\frac{\dot{m}_{\text {imp,total }}^{\prime \prime} \cdot\left(1-F_{\text {loss,total }}\right)}{\dot{m}_{\text {imp }, \text { liq }} \cdot n_{0}+\dot{m}_{\text {imp,ice }}^{\prime \prime}}
$$

The numerator of Eq. (16) is simply the impinging mass flux that sticks, while the denominator is the ice mass flux rate, which is the sum of the impinging liquid water mass flux that froze and impinging ice mass flux rate. Subtracting the quotient from " 1 " gives the fraction of ice mass flux that did not stick. Or put another way, it is the fraction of ice mass that is lost due to bounce and erosion. Eq. (16) can be also be formulated in terms of $\eta_{M R}$, and is shown in Eq. (17).

$$
n_{\text {loss }}=1-\frac{\left(1-F_{\text {loss }, \text { total }}\right)}{\eta_{M R} \cdot n_{0}+\left(1-\eta_{M R}\right)}
$$

In a similar fashion, combining Eqs. (13), (14) and (15), then rearranging for $n_{\text {loss }}$ provides the correlation for melt-dominated icing, and is shown in Eq. (18).

$$
n_{\text {loss }}=1-\frac{\dot{m}_{\text {imp,total }}^{\prime \prime} \cdot\left(1-F_{\text {loss }, \text { total }}\right)}{\dot{m}_{\text {imp }, i c e} \cdot\left(1-m_{0}\right)}
$$

Again, the numerator of Eq. (18) is the impinging mass flux that sticks, while the denominator is the unmelted ice mass flux rate. Yet again, subtracting the quotient from " 1 " gives the fraction of ice mass flux that did not stick, or the fraction of ice mass that is lost due to bounce combined with any erosion. Eq. (18) can be also be formulated in terms of $\eta_{M R}$, and is shown in Eq. (19).

$$
n_{\text {loss }}=1-\frac{\left(1-F_{\text {loss }, \text { total }}\right)}{\left(1-\eta_{M R}\right) \cdot\left(1-m_{0}\right)}
$$

Solving for the unknown values of $n_{\text {loss }}$, and $n_{0}$ or $m_{0}$, provides information on the amount of mass flux that is lost due to splash and runback. For freeze-dominated icing, the fraction of impinging mass flux that does not stick due to splash and runback, $F_{l o s s, s p l / r b}$, can be determined from the amount of impinging liquid mass flux that does not freeze, and is shown in Eq. (20).

$$
F_{\text {loss }, s p l / r b}=1-\frac{\dot{m}_{\text {imp,liq }}^{\prime \prime} \cdot\left(1-n_{0}\right)}{\dot{m}_{\text {imp }, \text { total }}}
$$

For melt-dominated icing, the fraction of impinging mass flux that does not stick due to splash and runback, is determined using the amount of impinging liquid mass flux along with the ice mass flux that melted, and is shown in Eq. (21).

$$
F_{l o s s, s p l / r b}=1-\frac{\dot{m}_{\text {impliq }}^{\prime \prime}+\dot{m}_{\text {imp }, i c e}^{\prime \prime} \cdot m_{0}}{\dot{m}_{\text {imp }, \text { total }}^{\prime \prime}}
$$

\section{Icing Surface Equilibrium Temperature Derivation}

For Eqs. (1) through Eq. (13), the thermodynamic model centered on the energy available for freezing or melting (latent energy), where the icing surface temperature was $T_{\text {surf }}=0{ }^{\circ} \mathrm{C}$. Bartkus et al. [17] stated that for conditions that were sufficiently cold and freeze fraction values were calculated to be $n_{0}=1$, then the icing surface temperature at the stagnation point could continue to decrease below $0{ }^{\circ} \mathrm{C}$ until it reached a thermodynamic equilibrium temperature. The derivation of that equilibrium temperature is provided in Eq. (22).

$$
q_{\text {sens,ice }}^{\prime \prime}+q_{\text {freeze }}^{\prime \prime}=q_{\text {evap }}^{\prime \prime}-q_{\text {conv }}^{\prime \prime}-q_{\text {kinetic }}^{\prime \prime}-q_{\text {cond }}^{\prime \prime}
$$

Equation (22) expands the expression in Eq. (1) by including the sensible heat surface energy for frozen ice, $q_{\text {sens,ice }}^{\prime \prime}$, and allowing cooling of the iced surface below $0{ }^{\circ} \mathrm{C}$. The other surface energy terms in Eq. (22) are the same as previously defined in Eqs. (1) through Eq. (7). The $q_{\text {sens,ice }}^{\text {" }}$ term can be expanded further and is shown in Eq. (23).

$$
q_{\text {sens }, \text { ice }}^{\prime \prime}=\dot{m}_{\text {stick }}^{\prime \prime} \cdot C p_{\text {ice }} \cdot\left(T_{\text {surf }}-T_{\text {freeze }}\right)
$$


In Eq. (23), $C p_{i c e}$ is the specific heat of the ice which is approximated to be constant with temperature, and $T_{\text {freeze }}$ is the temperature at which water freezes (i.e. $0^{\circ} \mathrm{C}$ ). In Eq. $(24), \dot{m}_{\text {stick }}{ }$ is expanded further as defined by freeze-dominated icing mass balance equation. As a reminder, sub-freezing surface temperatures can only occur in freeze-dominated icing. In addition, $n_{0}=1$ by definition for this sensible heat cooling, and therefore portions of the expression can be reduced. In the final formulation in Eq. (24), $\dot{m}_{\text {imp,total }}^{\prime \prime}$ is expressed in terms of total water content, collection efficiency at the stagnation line, particle mass velocity, and $n_{\text {loss }}$.

$$
\begin{gathered}
q_{\text {sens }, \text { ice }}^{\prime \prime}= \\
\left(\dot{m}_{\text {imp }, \text { liq }}^{\prime \prime} \cdot n_{0}+\dot{m}_{\text {imp }, \text { ice }}^{\prime \prime}\right) \cdot\left(1-n_{\text {loss }}\right) \cdot C p_{\text {ice }} \cdot\left(T_{\text {surf }}-T_{\text {freeze }}\right) \\
=\left(\dot{m}_{\text {imp,total }}^{\prime \prime}\right) \cdot\left(1-n_{\text {loss }}\right) \cdot C p_{\text {ice }} \cdot\left(T_{\text {surf }}-T_{\text {freeze }}\right) \\
=T W C \cdot \beta_{0} \cdot U \cdot\left(1-n_{\text {loss }}\right) \cdot C p_{\text {ice }} \cdot\left(T_{\text {surf }}-T_{\text {freeze }}\right)
\end{gathered}
$$

With the solved freeze fraction value of $n_{0}=1$ for these sufficiently cold cases, the unknown values become $n_{\text {loss }}$ and $T_{\text {surf }}$. The surface energy terms of $q_{\text {sens,ice }}^{\prime \prime}, q_{c o n v}^{\prime \prime}, q_{\text {cond }}^{\prime \prime}$, and $q_{\text {evap }}^{\prime \prime}$ in Eq. (22) are all functions of $T_{\text {surf }}$. Therefore, the unknown values of $n_{\text {loss }}$ and $T_{\text {surf }}$ must be determined by iteratively solving Eq. (12) and Eq. (24), where experimental growth rate data is used with respect to Eq. (12). The resulting solved value of $T_{\text {surf }}$ is the thermodynamic equilibrium icing surface temperature.

\section{Model Assessment with Experimental Data}

The following sections present an assessment of the thermodynamic model utilizing experimental data from fundamental icing physics testing conducted at the NASA PSL in 2018. The thermodynamic model is evaluated using data measured at various velocities, pressures, humidities, temperatures, and melt ratios. Struk et al. [3] provides a description of the test facilities and experiments in an accompanying paper. The experiments generated a set of ice shapes on a NACA 0012 airfoil under well-characterized conditions. At the center of the icing experiments were four sets of relative humidity $(R H)$ sweeps. The model will be evaluated utilizing accretion data on the $0.267 \mathrm{~m}$ (10.5 in) chord airfoil, where tests were conducted with a $0^{\circ}$ angle of attack (AOA). The assessment will focus on times after which the initial temperature difference between the airfoil leading edge temperature and ice temperature became negligible. According to Bartkus [17] this initial conductive heat transfer between the airfoil and accreting ice occurs primarily during the first $20 \mathrm{~s}$ of airfoil exposure to the icing cloud. This assessment will look at accretions beyond the initial transient time period. The following will present sections on the experimental conditions, experimental analysis, and finally the thermodynamic model evaluation.

\section{Experimental Conditions}

Ice shapes were generated across a series of four different flow conditions where the relative humidity in the plenum of PSL was the primary parameter varied. Table 1 provides the initial test conditions for the four $R H$ test sweeps. Four icing tests (labeled as Case A through Case D) were conducted for each $R H$ test sweep. For convenience, each $R H$ test sweep will be referred to as Test Condition Series (TCS-1 through TCS-4) for the remainder of the paper, and may be coupled with an individual case letter (i.e. TCS-1.A) for quick reference to a Page 6 of 17 particular case of a series. A total of 16 icing tests were conducted for these four series. The tunnel exit target velocity, $U_{\text {targ, }}$ plenum pressure, $p_{P L, t a r g}$, and plenum temperature, $T_{P L \text {,targ, }}$ represent the target values for each Test Condition Series. The plenum relative humidity values, $R H_{P L}$, are as measured in the tunnel plenum. As can be seen from Table 1, tests were conducted at 3 different target velocities $(85 \mathrm{~m} / \mathrm{s}, 135 \mathrm{~m} / \mathrm{s}$, and $185 \mathrm{~m} / \mathrm{s})$, and at two target total pressures $(44.8 \mathrm{kPa}$ and $87.5 \mathrm{kPa})$. The target air flow speeds equate to Mach values of $0.25,0.40$, and 0.56 respectively. Not listed in the table, but important to mention, the injected particle size distribution was held constant for each test with an approximate initial median volumetric diameter, $M V D$, of $20 \mu \mathrm{m}$. In addition, the injected $T W C$ was held constant for each test, with a target value of $2.0 \mathrm{~g} / \mathrm{m}^{3}$. The column labeled Escort File \# (or Esc\# for short) in Table 1 is the test run number system used during testing. It should be noted that since flow

\begin{tabular}{|c|c|c|c|c|c|c|}
\hline $\begin{array}{c}\text { TCS } \\
\# \\
\end{array}$ & $\begin{array}{l}U_{\text {targ }} \\
\mathrm{m} / \mathrm{s}\end{array}$ & $\begin{array}{c}p_{P L, t a r g} \\
\mathrm{kPa} \\
\text { (psia) }\end{array}$ & $\begin{array}{c}T_{P L, \text { targ }} \\
{ }^{\circ} \mathrm{C} \\
\left({ }^{\circ} \mathrm{F}\right)\end{array}$ & Case & $\begin{array}{c}R H_{P L} \\
\% \\
\%\end{array}$ & $\begin{array}{c}\text { Escort } \\
\text { File } \\
\#\end{array}$ \\
\hline \multirow{4}{*}{1} & \multirow{4}{*}{85} & \multirow{4}{*}{$\begin{array}{l}44.8 \\
(6.5)\end{array}$} & \multirow{4}{*}{$\begin{array}{c}7.2 \\
(45)\end{array}$} & $\mathrm{A}$ & 0.4 & 60 \\
\hline & & & & B & 34.0 & 228 \\
\hline & & & & C & 36.9 & 72 \\
\hline & & & & $\mathrm{D}$ & 40.8 & 235 \\
\hline \multirow{4}{*}{2} & \multirow{4}{*}{135} & \multirow{4}{*}{$\begin{array}{l}44.8 \\
(6.5)\end{array}$} & \multirow{4}{*}{$\begin{array}{c}7.2 \\
(45)\end{array}$} & $\mathrm{A}$ & 20.6 & 170 \\
\hline & & & & B & 25.2 & 593 \\
\hline & & & & C & 30.2 & 171 \\
\hline & & & & $\mathrm{D}$ & 34.5 & 169 \\
\hline \multirow{4}{*}{3} & \multirow{4}{*}{185} & \multirow{4}{*}{$\begin{array}{l}44.8 \\
(6.5)\end{array}$} & \multirow{4}{*}{$\begin{array}{c}7.2 \\
(45)\end{array}$} & A & 28.1 & 187 \\
\hline & & & & $\mathrm{B}$ & 29.5 & 611 \\
\hline & & & & $\mathrm{C}$ & 31.4 & 214 \\
\hline & & & & $\mathrm{D}$ & 33.2 & 205 \\
\hline \multirow{4}{*}{4} & \multirow{4}{*}{135} & \multirow{4}{*}{$\begin{array}{c}87.5 \\
(12.7)\end{array}$} & \multirow{4}{*}{$\begin{array}{c}7.2 \\
(45)\end{array}$} & A & 5.2 & 618 \\
\hline & & & & B & 10.7 & 249 \\
\hline & & & & $\mathrm{C}$ & 15.0 & 243 \\
\hline & & & & $\mathrm{D}$ & 19.5 & 253 \\
\hline
\end{tabular}
velocity in the plenum is slow, plenum values can be approximated to be total conditions.

Table 1. Test conditions for the four $R H$ sweeps (Test Condition Series).

All plenum values in Table 1 refer to conditions upstream of the tunnel spray bars. It should be noted that while the conditions upstream of the spray bar in the tunnel plenum were maintained constant, as it has been previously reported [2-5], conditions downstream at the test section change with the activation of the spray cloud. Modeling efforts [19-23] show that a thermodynamic interaction between the icing cloud and flowing air results in changes in total air temperature, $T_{0}$, and humidity at the test section, compared with pre-spray conditions. In addition, changes occur in total water content, melt ratio and cloud particle size at the test section, compared with the initial spray conditions in the plenum. For the NASA 2018 experiments, whereas only humidity content was varied at the tunnel inlet (plenum), other parameters changed, most notably $T_{0}, T w b_{0}, \eta_{M R}, T W C$, and the cloud particle size distribution (and $M V D$ ). Due to the highly-coupled parameter set, the ideal experimental situation where one variable is isolated and varied independently was not possible.

Table 2 shows the measured and calculated conditions at the test section (i.e. just forward of the airfoil leading edge) after the icing cloud was activated, for all 16 icing tests. See Struk et al. [3] for a description of how these conditions were measured and calculated. In Table 2 , the humidity parameter, $M M R$, is the mass mixing ratio, which is the ratio of vapor mass to dry air mass. Not listed in Table 2 is that the cloud $M V D$ just forward of the airfoil leading edge was measured to be approximately $35 \mu \mathrm{m}$ for every test $[3,24]$. The value varied by just a few microns from case to case. It can be seen from Table 2 that 
within each TCS, the values of $T_{0}, T w b_{0}, \eta_{M R}, M M R$, and TWC increased as $R H_{P L}$ was increased. It should be noted that total conditions are provided in Table 1, but several of the energy expressions provided utilize static conditions.

Table 2. Conditions as measured and calculated just forward of the airfoil leading edge as the icing cloud was activated.

\begin{tabular}{|c|c|c|c|c|c|c|c|}
\hline $\begin{array}{c}\text { Test } \\
\text { Case }\end{array}$ & $\begin{array}{c}U \\
(\mathrm{~m} / \mathrm{s})\end{array}$ & $\begin{array}{c}T_{0} \\
\left({ }^{\circ} \mathrm{C}\right)\end{array}$ & $\begin{array}{c}p_{0} \\
(\mathrm{kPa})\end{array}$ & $\begin{array}{c}M M R \\
(\mathrm{~g} / \mathrm{kg})\end{array}$ & $\begin{array}{c}T w b_{0} \\
\left({ }^{\circ} \mathrm{C}\right)\end{array}$ & $\begin{array}{c}T W C \\
\left(\mathrm{~g} / \mathrm{m}^{3}\right)\end{array}$ & $\begin{array}{c}\eta_{M R} \\
(-)\end{array}$ \\
\hline \multicolumn{7}{|c|}{ Test Condition Series 1 } \\
\hline A & 84 & -1.0 & 44.7 & 3.9 & -5.5 & 1.2 & 0.03 \\
\hline B & 83 & 1.8 & 44.7 & 7.2 & -0.8 & 2.1 & 0.37 \\
\hline C & 83 & 2.1 & 44.8 & 7.5 & -0.4 & 2.1 & 0.57 \\
\hline D & 84 & 2.2 & 44.7 & 7.9 & 0.0 & 2.2 & 0.93 \\
\hline \multicolumn{7}{|c|}{ Test Condition Series 2 } \\
\hline A & 133 & 0.5 & 44.8 & 5.9 & -2.6 & 3.2 & 0.14 \\
\hline B & 133 & 1.1 & 44.7 & 6.3 & -1.9 & 3.4 & 0.21 \\
\hline C & 133 & 2.0 & 44.8 & 6.8 & -1.1 & 3.6 & 0.28 \\
\hline D & 133 & 2.1 & 44.8 & 7.1 & -0.8 & 3.8 & 0.51 \\
\hline \multicolumn{7}{|c|}{ Test Condition Series 3 } \\
\hline A & 182 & 3.0 & 44.8 & 6.2 & -1.4 & 4.1 & 0.29 \\
\hline B & 182 & 3.6 & 44.7 & 6.5 & -1.0 & 4.2 & 0.31 \\
\hline C & 182 & 3.6 & 44.8 & 6.6 & -0.8 & 4.2 & 0.41 \\
\hline D & 182 & 3.9 & 44.8 & 6.7 & -0.6 & 4.3 & 0.53 \\
\hline \multicolumn{7}{|c|}{ Test Condition Series 4 } \\
\hline A & 133 & 2.4 & 87.5 & 2.6 & -1.4 & 2.9 & 0.32 \\
\hline B & 133 & 2.5 & 87.5 & 2.9 & -0.9 & 3.2 & 0.40 \\
\hline C & 133 & 2.5 & 87.5 & 3.1 & -0.7 & 3.3 & 0.65 \\
\hline D & 133 & 3.0 & 87.5 & 3.3 & -0.1 & 3.5 & 0.91 \\
\hline
\end{tabular}

\section{Experimental Analysis}

Analysis of the accreted ice was performed for each icing test and is utilized for this paper to better understand the icing process. Videos of the ice accretion were recorded at two perpendicular angles. Figure 1 shows images of the ice accretion from both camera angles. Figure 1a shows the accretion along the span (span-view), Fig. 1b shows the two-dimensional accretion from the side of the airfoil (profile-view). In Fig. 1a, the light gray mid-section region $(\sim 10.5 \mathrm{~cm}$ in width) is the main icing target area (a hollow titanium alloy shell), while the dark regions on either side of the mid-section are the airfoil extensions (solid aluminum). Leading edge ice growth rates were measured from both perspectives, however, only the span-view ice growth rate at the midspan is utilized for this analysis. The span-view camera was able to capture the entire ice growth, including the initial growth, while the profile-view was unable to capture the initial ice growth (approximately the initial $2.5 \mathrm{~mm}$ ) due to blind spots that result from optical perspective effects. Profile-view images were backlit to provide good contrast between the iced airfoil and background for imaging analysis purposes. Ice shape analysis also included measuring the leading edge ice accretion angle. This was measured utilizing the profile-view images and generating two line segments along the leading edge. Each line segment extended about $4 \mathrm{~mm}$ on opposite sides of the leading edge. The two line segments produced the leading edge ice accretion angle, $\varphi$, and can be seen in Fig. 1b. Thermocouple $(\mathrm{T} / \mathrm{C})$ data that measured airfoil surface temperatures was also analyzed. Several thermocouples were affixed to the surface of the airfoil, however the leading edge thermocouple at the airfoil midspan is the primary thermocouple of interest for this analysis.
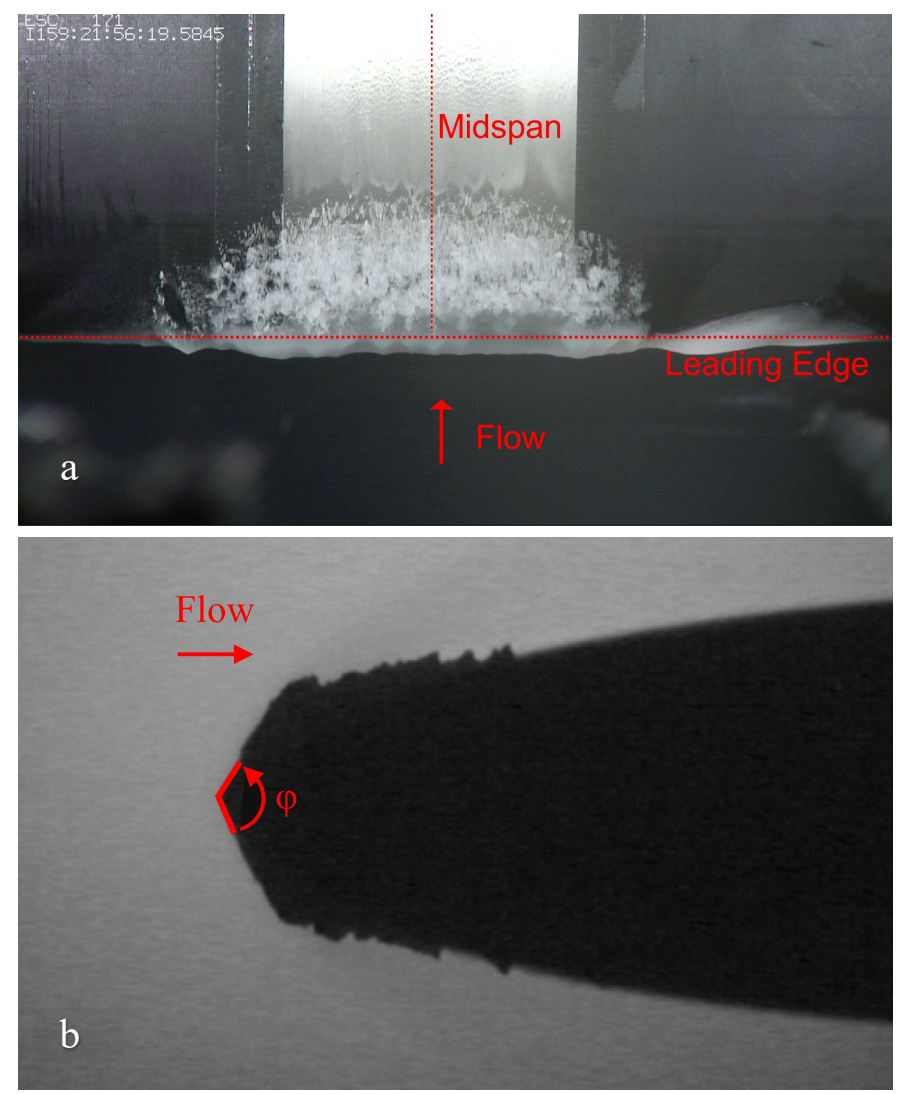

Figure 1. Image of ice accretion from the a) span-view and b) profile-view.

Figure 2 through Fig. 5 show profile-view ice accretions of the four Test Condition Series. The ice shapes at $240 \mathrm{~s}$, and at the end of test (generally near $600 \mathrm{~s}$ ) are shown for each case. Two tests were terminated short of $600 \mathrm{~s}$, as no accretion was observed on the midsection of the airfoil. These two tests are noted in the captions. Three of the images show ice accretion that occurred on the airfoil extension (denoted by red ovals). These ice accretions on the extension were dismissed from ice accretion analysis since they did not occur on the mid-section of the airfoil. Cases A through Case D for each Test Condition Series (TCS-1 through TCS-4) along with the time in seconds from the start of spray activation are shown in the bottom left corner of each image. The earlier image (left) also lists the melt ratio in the bottom corner as well for reader convenience. These images are shown to provide the reader a general idea of ice shape and growth. In general, the figures show that as melt ratio increased for each Test Condition Series, the ice shape grew in size and also changed from a pointy wedge-like shape to a blunt shape. Precursors of double-horn shapes are noticeable and more prevalent in the higher melt ratio conditions, and higher velocity conditions. A full double-horn ice shape formed in Case D of TCS-4. Some of the ice shapes became quite irregular beyond 240 seconds of ice cloud exposure.

Page 7 of 17 


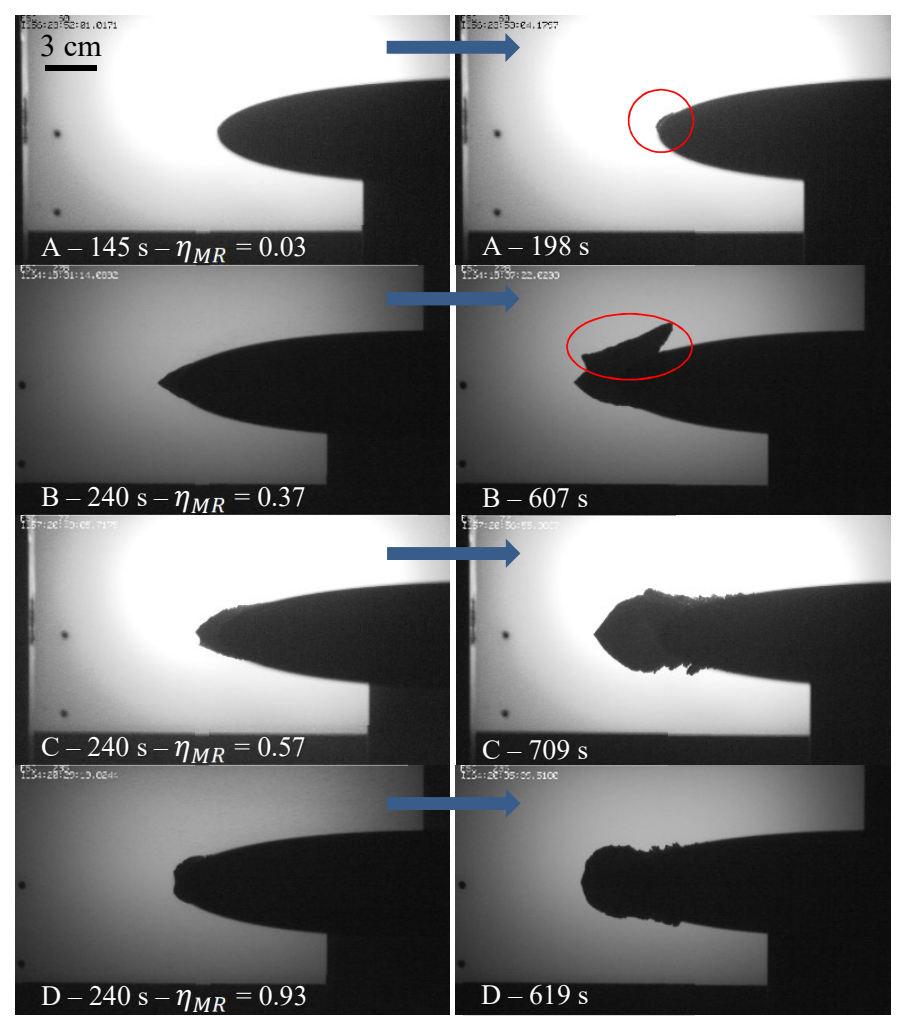

Figure 2. Profile ice shapes for TCS-1 at $240 \mathrm{~s}$ and at the end of test (generally near $600 \mathrm{~s}$ ). The red circles show accretion on the airfoil extension. The Case (A through D) along with time of ice exposure is shown in the bottom left of every image.

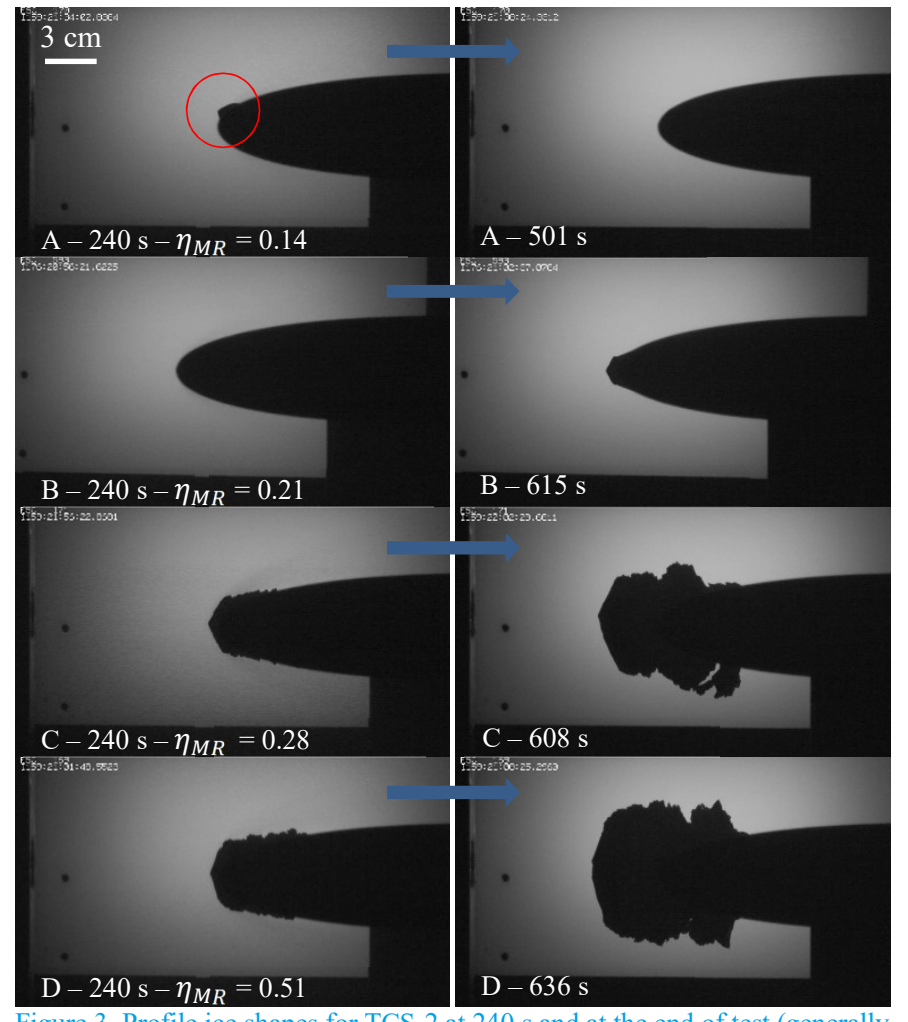

Figure 3. Profile ice shapes for TCS-2 at $240 \mathrm{~s}$ and at the end of test (generally near $600 \mathrm{~s}$. The red circle shows accretion on the airfoil extension. The Case (A through D) along with time of ice exposure is shown in the bottom left of every image.

Page 8 of 17



Figure 4. Profile ice shapes for TCS-3 at $240 \mathrm{~s}$ and at the end of test (generally near $600 \mathrm{~s}$ ). The Case (A through D) along with time of ice exposure is shown in the bottom left of every image.

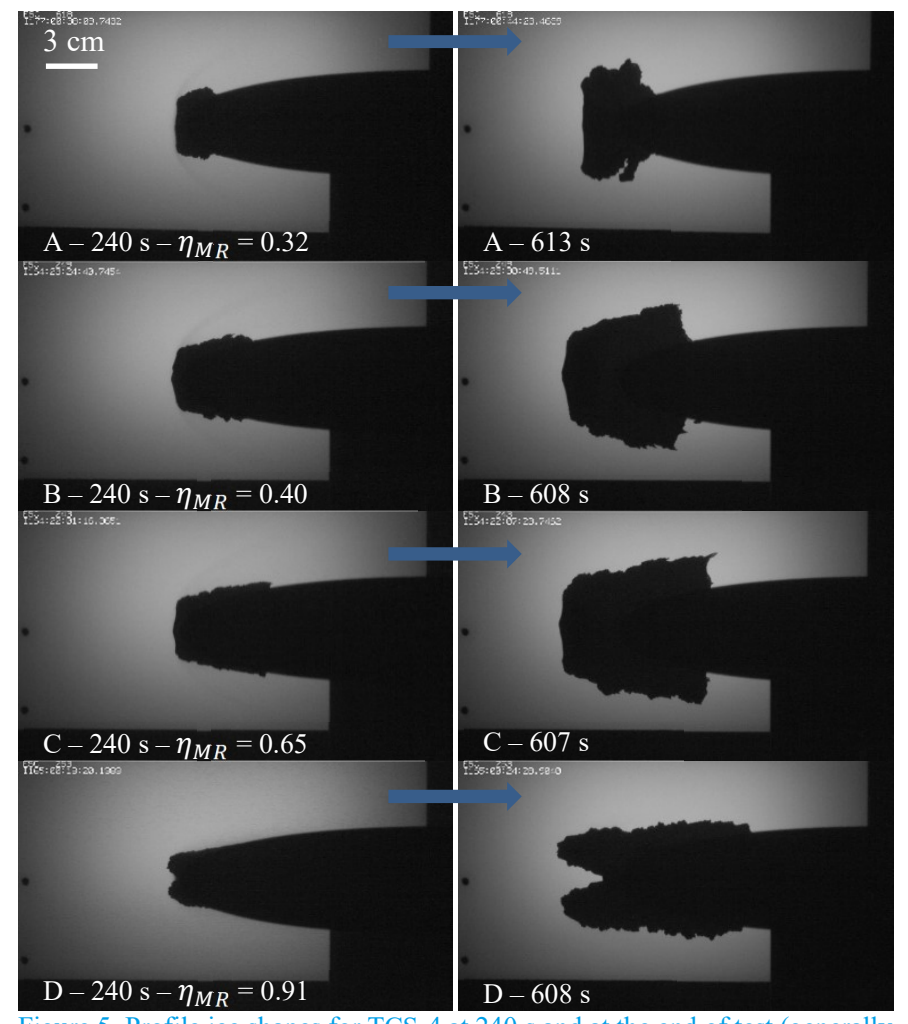

Figure 5. Profile ice shapes for TCS-4 at $240 \mathrm{~s}$ and at the end of test (generally near $600 \mathrm{~s}$ ). The Case (A through D) along with time of ice exposure is shown in the bottom left of every image. 

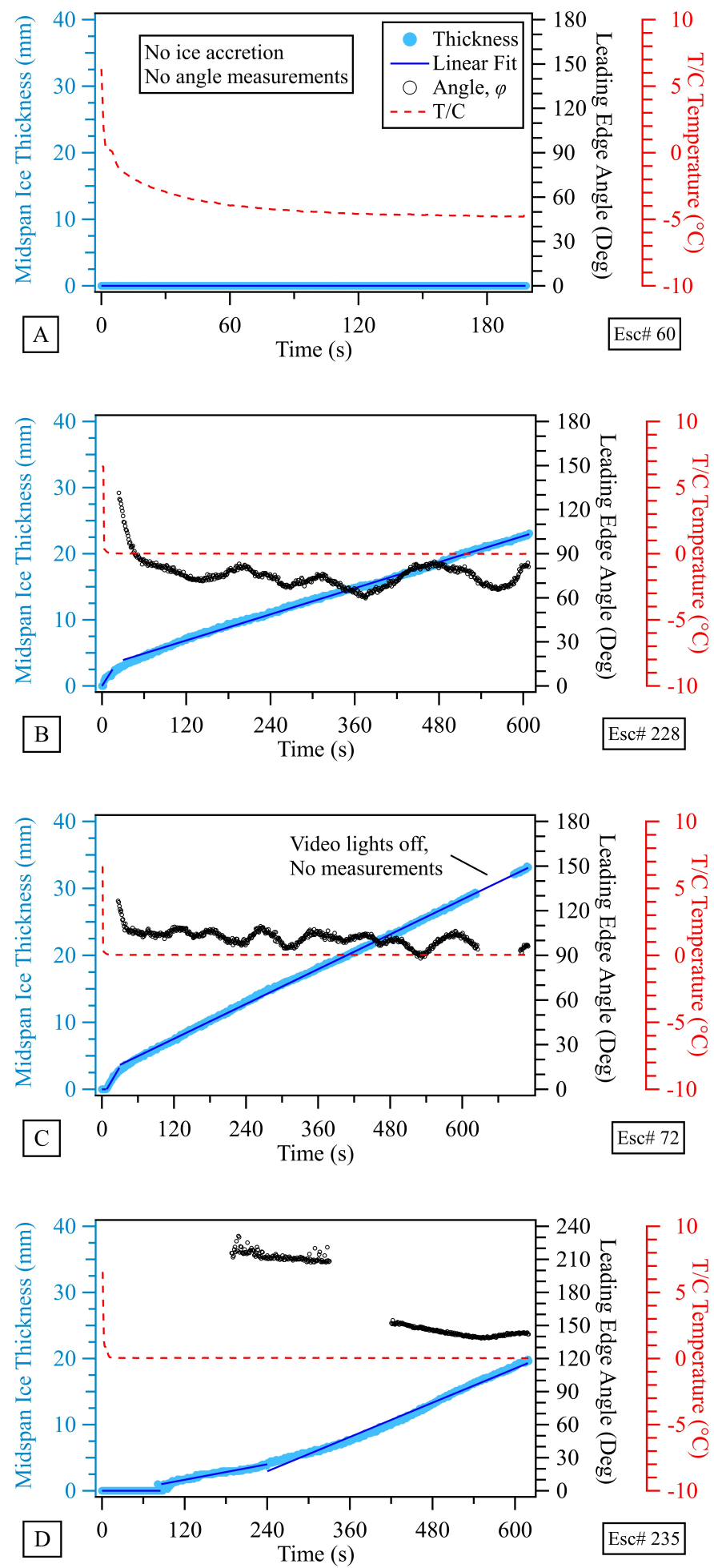

Figure 6. Analyzed data for TCS-1 (Case A through Case D). Analysis includes midspan ice thickness (with linear fits), leading edge ice accretion angle, and leading edge thermocouple temperature data.
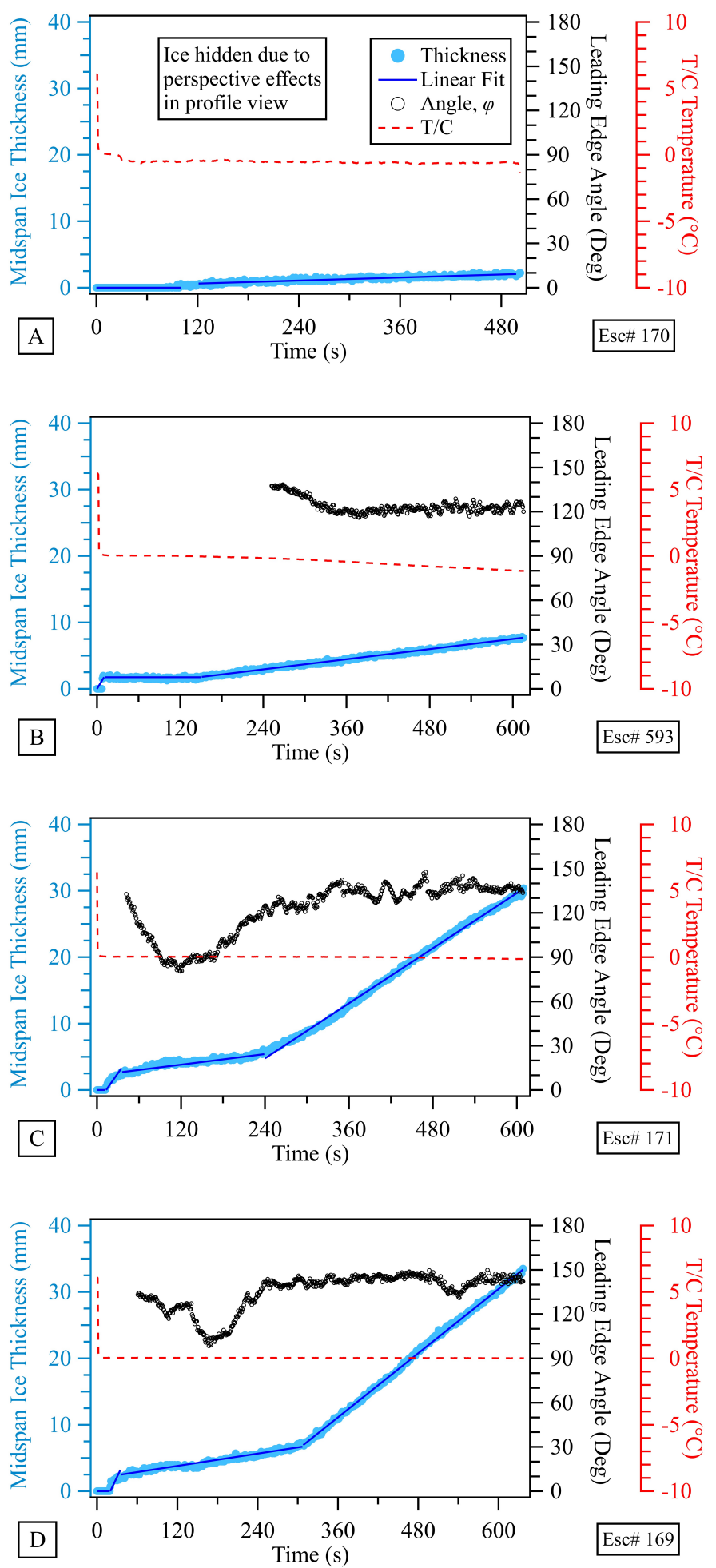

Figure 7. Analyzed data for TCS-2 (Case A through Case D). Analysis includes midspan ice thickness (with linear fits), leading edge ice accretion angle, and leading edge thermocouple temperature data. 

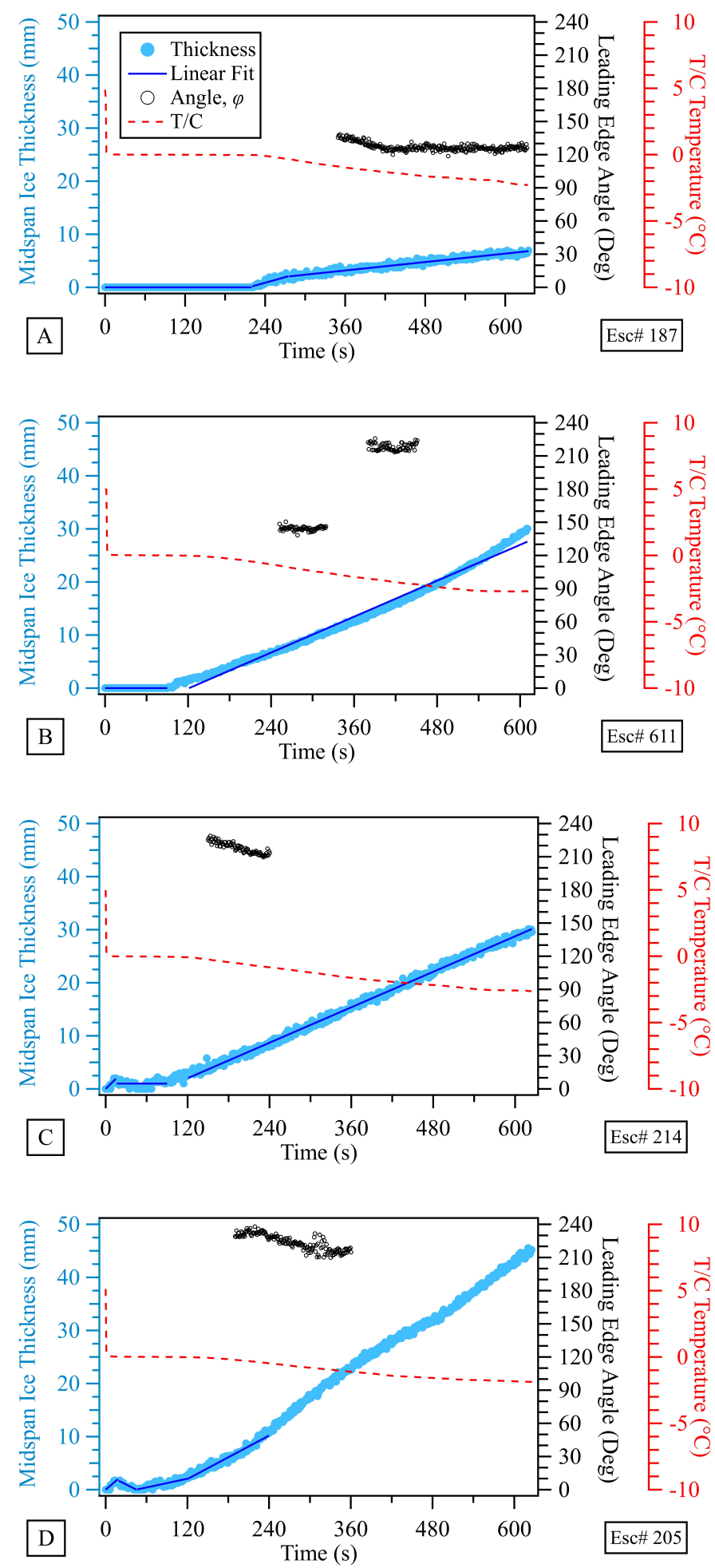

Figure 8. Analyzed data for TCS-3 (Case A through D). Analysis includes midspan ice thickness (with linear fits), leading edge ice accretion angle, and leading edge thermocouple temperature data.
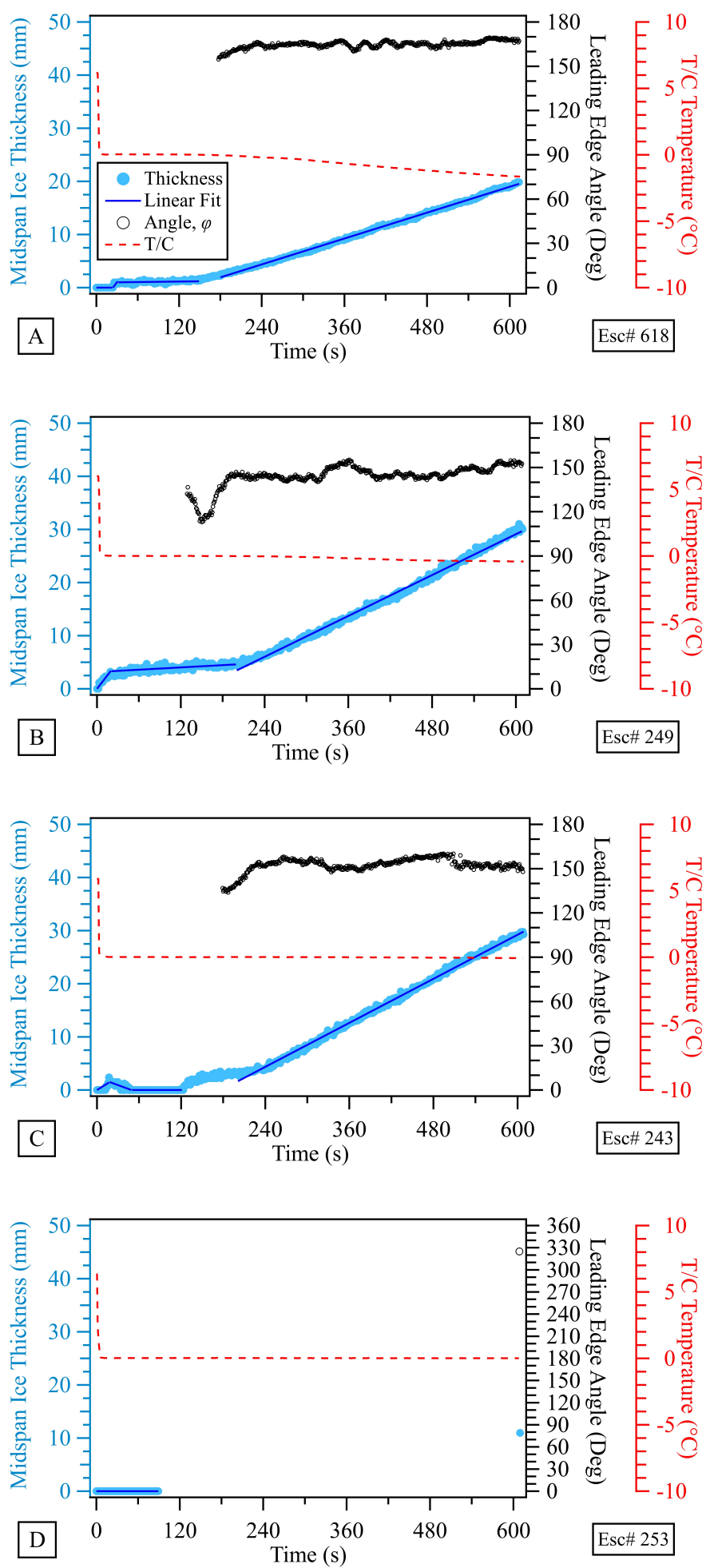

Figure 9. Analyzed data for TCS-4 (Case A through D). Analysis includes midspan ice thickness (with linear fits), leading edge ice accretion angle, and leading edge thermocouple temperature data. 
Figure 6 through Fig. 9 show analyzed data for Case A through D for each Test Condition Series (TCS-1 through TCS-4). Analysis includes midspan ice thickness (from span-view profile images), leading edge ice accretion, angle and leading edge thermocouple data with respect to ice cloud activation time. Several linear fits are fitted to the ice thickness for each case. The slope of each line represents the approximate ice growth rate $(\mathrm{mm} / \mathrm{s})$ for the respective time period.

There are several observations and points to be made for Figs. 6 - 9 . Firstly, of all the cases shown in Figs. 6 - 9, only case TCS-1.A did not accrete any ice, presumably because the melt ratio for the test was too low to accrete ice. A second point, the leading edge ice thickness for TCS-4.D (the double-horn test) in Fig. 9 was only measured for the initial period (ice thickness $=0 \mathrm{~mm}$ ), prior to the onset of the double-horn ice growth. The view of the leading edge (inside the double-horn) was obscured by a cloud debris field for a majority of the test, and therefore was not measured (along with the leading edge accretion angle). A single measurement of leading edge ice thickness and angle was made when the cloud was turned off and a clean view of the accretion was imaged at the end of TCS-4.D. Next, aside for two cases (TCS-1.B and TCS-1.C) in Fig. 6, each test experienced a period of no growth or slow growth at or near the start of ice cloud activation. This period of leading edge no/slow growth lasted anywhere from $60 \mathrm{~s}$ to $240 \mathrm{~s}$ in some cases. It was observed that ice accretion further downstream on the airfoil grew forward during these leading edge no/slow growth periods. As that downstream ice reached near the leading front plane of the airfoil, the leading edge ice growth experienced an increase in rate. A final observation from these figures is that the ice did not reach a maximum ice size for any case where ice accretion occurred.

Leading edge ice accretion angle was measured for periods where the leading edge was visible for Fig. 6 through Fig. 9. Utilizing the profile-view, the ice accretion only became visible once it reached approximately $2.5 \mathrm{~mm}$ in thickness, as optical perspective effects (as discussed earlier) created a blind region. Therefore, it was not possible to measure this angle for the beginning of each test, sometimes up to several hundred seconds for some cases. The ice shape near the leading edge became irregular at times, and therefore the accretion angle was not measured for these periods. In general, the ice shape became more irregular as $\eta_{M R}$ and $U$ increased. Precursors to double-horn shapes (and fully developed double-horn shapes) had $\varphi$ values greater than $180^{\circ}$. For TCS- 1 and TCS-2, some trends are noticeable regarding the leading edge accretion angle, $\varphi$. First is that $\varphi$ reaches a near steady-state angle towards the end of each test. Also, $\varphi$ increased in value as $\eta_{M R}$ increased for TCS- 1 and TCS-2. The lower $\varphi$ values are likely due to erosion effects at lower $\eta_{M R}$ values. Comparing $\varphi$ with leading edge growth rate, one can see that larger leading edge ice angle values are accompanied by higher ice growth rates. TCS-2.C illustrates this coupled trend well. During the slow growth period, $\varphi$ reaches its lowest value (perhaps the decreasing $\varphi$ value is indicative of some erosion effects during this slow growth period), then as $\varphi$ increased, ice growth rate increases. Both the angle and growth rate reach a steady value beyond the $360 \mathrm{~s}$ mark in the test. Another trend noticeable is that larger $\varphi$ values occurred at higher velocities. Finally, larger $\varphi$ values occurred for the higher pressure cases (TCS-4) compared to the lower pressure cases (TCS-2).

Thermocouple temperature data at the airfoil midspan leading edge was plotted for each case in Fig. 6 through Fig 9. In general, the pre-spray $\mathrm{T} / \mathrm{C}$ temperature for all 16 cases measured about $6{ }^{\circ} \mathrm{C}$ above freezing. This is the approximately the pre-spray air total temperature. The $\mathrm{T} / \mathrm{C}$ responded quickly and reached $0{ }^{\circ} \mathrm{C}$ within seconds of cloud activation. This reading of $0{ }^{\circ} \mathrm{C}$ is generally expected for mixed-phase icing tests. For some tests, generally the highest velocity cases (TCS-3) Page 11 of 17 and colder cases (lowest $T_{0}$ and $T w b_{0}$ cases), the T/C temperature decreased below $0{ }^{\circ} \mathrm{C}$. There are two likely reasons for these sub-freezing readings. The first reason for sub-freezing thermocouple readings, is that for the coldest $T_{0}$ and $T w b_{0}$ cases, the energy surface balance equations will show that the icing surface should decrease below $0{ }^{\circ} \mathrm{C}$. These surface energy equilibrium temperature equations were previously discussed, and will be evaluated later in the paper. The second explanation is due to conduction from colder sections of the airfoil, downstream of the leading edge, and generally relates to higher velocity cases. The temperature recovery factor aft of the leading edge in the boundary layer is expected to be less than one. Due to lower temperature recovery factors, airfoil metal temperatures will be colder downstream of the leading edge. Eventually conduction of heat from the leading edge towards those lower metal temperature regions drive the leading edge $\mathrm{T} / \mathrm{C}$ temperature down. This is most prevalent for the highest velocity condition (TCS-3), where temperature recovery will be the lowest aft of the leading edge. The hypothesis of metal conduction within the airfoil will be evaluated later in the paper as well.

\section{Sticking Efficiency Analysis}

It is instructive to look at ice accretions at several times, namely at $60 \mathrm{~s}, 240 \mathrm{~s}$, and $600 \mathrm{~s}$, to see how sticking efficiency changes with time. The corresponding ice growth rates $-\dot{t}_{60 s}, \dot{t}_{240 s}$, and $\dot{t}_{600}$ respectively - for all 16 cases are shown in Table 3 . The same growth rate may apply for multiple periods for any individual case.

Table 3. Ice growth rates for all cases as measured at $60 \mathrm{~s}, 240 \mathrm{~s}$, and $600 \mathrm{~s}$.

\begin{tabular}{|c|c|c|c|}
\hline Case & $\begin{array}{c}\dot{t}_{60 s} \\
(\mathrm{~mm} / \mathrm{s})\end{array}$ & $\begin{array}{r}\dot{t}_{240 s} \\
(\mathrm{~mm} / \mathrm{s})\end{array}$ & $\begin{array}{c}\dot{t}_{600 s} \\
(\mathrm{~mm} / \mathrm{s})\end{array}$ \\
\hline \multicolumn{5}{|c|}{ Test Condition Series 1 } \\
\hline A & 0.000 & 0.000 & N/A \\
\hline B & 0.033 & 0.033 & 0.033 \\
\hline C & 0.043 & 0.043 & 0.043 \\
\hline D & 0.000 & 0.020 & 0.043 \\
\hline \multicolumn{5}{|c|}{ Test Condition Series 2 } \\
\hline A & 0.000 & 0.004 & 0.004 \\
\hline B & 0.000 & 0.013 & 0.013 \\
\hline C & 0.013 & 0.013 & 0.069 \\
\hline D & 0.015 & 0.015 & 0.081 \\
\hline \multicolumn{5}{|c|}{ Test Condition Series 3 } \\
\hline A & 0.000 & 0.035 & 0.013 \\
\hline B & 0.000 & 0.056 & 0.056 \\
\hline C & 0.002 & 0.056 & 0.056 \\
\hline D & 0.028 & 0.069 & 0.069 \\
\hline \multicolumn{5}{|c|}{ Test Condition Series 4 } \\
\hline A & 0.005 & 0.041 & 0.041 \\
\hline B & 0.010 & 0.064 & 0.064 \\
\hline C & 0.000 & 0.063 & 0.063 \\
\hline D & 0.000 & N/A & N/A \\
\hline
\end{tabular}


Sticking efficiency is plotted against melt ratio for the four test cases at $60 \mathrm{~s}, 240 \mathrm{~s}$ and $600 \mathrm{~s}$ in Fig. 10.There are several key points to take away from Fig. 10. First is that the sticking efficiency was the lowest for the earliest time period (Fig. 10a - $60 \mathrm{~s}$ ), while the highest $\eta_{\text {stick }}$ values occurred towards the end of the test (Fig. 10c-600 s). This low sticking efficiency in Fig. 10a corresponds with the no/slow growth that occurred during the first few minutes for most tests, which was highlighted in the previous experimental analysis section. The two points of TCS-1 (Case B and Case C) with higher $\eta_{\text {stick }}$ values during the early time period correspond to points that did not experience a no/slow growth. As noted earlier, when ice downstream of the leading edge grew forward reaching the leading edge plane, the leading edge ice growth rates increased. Fig. 10b and 10c illustrate this higher growth rates with higher sticking efficiency values. A plateau of icing severity (where severity relates to higher $\eta_{\text {stick }}$ values) begins to emerge at later times for each Test Condition Series. According to Fig. $10 \mathrm{c}$, the $\eta_{\text {stick }}$ plateau value depends on the TCS. The plateau decreases with increasing velocity where $\eta_{\text {stick }}$ plateau values are approximately $0.21,0.15$, and 0.07 for TCS-1, TCS-2, and TCS-3 respectively. Again, the measured velocities for these three Test Condition Series are $U=84 \mathrm{~m} / \mathrm{s}, 133 \mathrm{~m} / \mathrm{s}$, and $182 \mathrm{~m} / \mathrm{s}$ respectively. Fig. 10c shows that approximately the same plateau $\eta_{\text {stick }}$ values were measured for the two different total pressure cases. Again, the total pressures for TCS-2 and TCS-4 are $p_{0}=44.8 \mathrm{kPa}$ and $87.5 \mathrm{kPa}$, respectively. It is not clear if an upper $\eta_{M R}$ limit exists with mixed-phase icing for the conditions run in these experiments. The point plotted with the highest melt ratio (TCS-1.D, $\left.\eta_{M R}=0.92\right)$ may have been experiencing supercooled liquid icing. A sufficient number of tests were not conducted to identify if a maximum $\eta_{M R}$ mixed-phase icing limit exists. Despite that lone point, the plateau, in general ranged from approximately $\eta_{M R}=0.30$ to at least $\eta_{M R}=0.65$. Fig. $10 \mathrm{c}$ shows that the onset of icing is pushed to the right (towards higher melt ratio values) with increasing velocity, although the uncertainty in melt ratio measurements precludes this from being definitive. Should this trend be correct, the shift to more severe icing with respect to melt ratio may be explained by greater amounts of erosion occurring at higher velocities at lower $\eta_{M R}$ values.
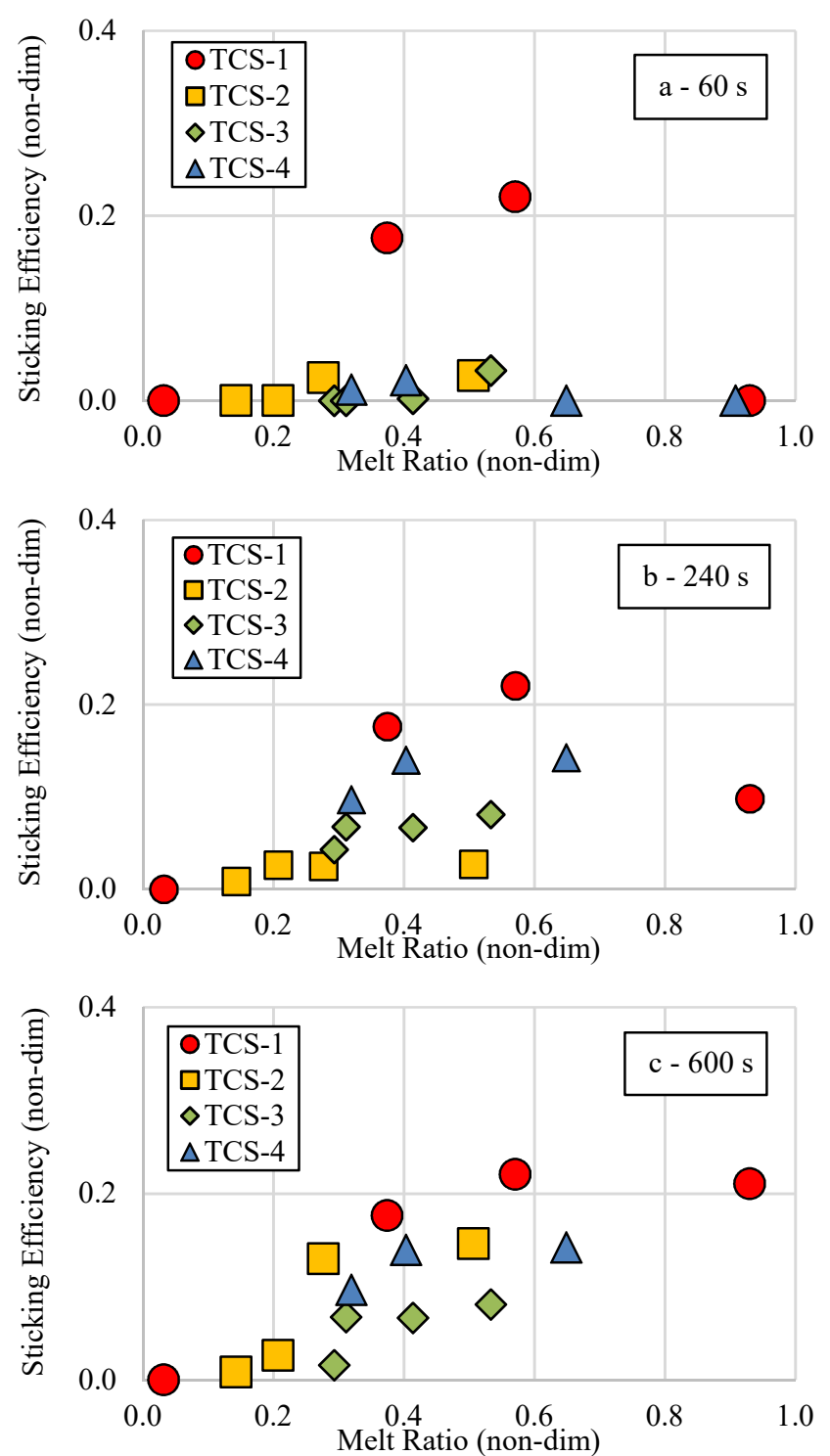

Figure 10. Sticking efficiency vs melt ratio at for all 16 cases at a) 60 s, b) 240 $\mathrm{s}$, and c) $600 \mathrm{~s}$.

It should be noted that the case where no ice accretion was observed and terminated after $198 \mathrm{~s}$ of cloud exposure (TCS-1.A) is plotted in all three plots. It is momentarily assumed that no ice would grow at any time under those conditions, and is plotted in the graphs to illustrate that there exists a lower melt ratio boundary where icing will not occur. The fully developed double-horn test (TCS-4.D) is not plotted in Fig $10 \mathrm{~b}$ and $10 \mathrm{c}$ as ice growth rates at the leading edge of the airfoil could not be measured.

\section{Thermodynamic Model Assessment}

As mentioned earlier, this assessment focuses on time periods after the initial temperature transient period. The thermodynamic model will be evaluated at $240 \mathrm{~s}$ as this was generally a good compromise with ice accretion size. Zero or small ice accretion rates occurred early in most tests, while large irregular shapes that did not conform to the dry airfoil shape often occurred at later times in a test. Not many interesting results can be extracted from zero or very slow growth rates. Also, when ice shapes become excessively large and irregular, the

Page 12 of 17 
coefficients of heat and mass transfer used in the model (which assumes an approximate dry airfoil geometry) become less applicable. For these reasons, the model will be evaluated at $240 \mathrm{~s}$.

\section{Freeze Fraction and Melt Fraction Analysis}

The thermodynamic ice crystal icing model was run for 15 of the 16 cases (the fully developed double-horn case TCS-4.D was not evaluated) using the test conditions provided in Table 2, along with the ice growth rate at $240 \mathrm{~s}, \dot{t}_{240 \mathrm{~s}}$, presented in Table 3 . Figure 11 shows the calculated freeze fraction or melt fraction as determined from the model, plotted against the measured total wet-bulb temperature just upstream of the airfoil. The large, solid symbols in Fig. 11 represent cases that experienced freeze-dominated icing, while the smaller empty symbols represent melt-dominated cases. The color of the symbol is grouped with the Test Condition Series. It can be seen that the there is a transition between melt-dominated and freeze-dominated icing around -0.5 to $-1.0{ }^{\circ} \mathrm{C}$ (depending on condition). In general, $T w b_{0}$ is a good first-order indicator for determining the type of icing that will occur. Sub-freezing $T w b_{0}$ values generally indicate freeze-dominated icing, while above freezing values indicate melt-dominated icing. Melt-dominated icing shifts slightly into the sub-freezing $T w b_{0}$ domain due to the transfer of kinetic energy from a fast moving particle to a stationary ice accretion surface. It can be seen that higher velocity cases pushed further into the sub-freezing $T w b_{0}$ domain, up to $-0.8^{\circ} \mathrm{C}$ for one of the highest velocity cases (TCS-3.B). A slight trend is noticeable with the freeze-dominated (large, solid) points. As $T w b_{0}$ decreases, the freeze fraction increases. This is expected for two reasons. The first is that the colder the condition, the more readily the liquid water will freeze into ice. Secondly, since it was not possible to isolate conditions, as humidity in the tunnel plenum was decreased, not only did $T w b o$ decrease, but so did $\eta_{M R}$. With small amounts of liquid water available to freeze at lower $\eta_{M R}$ values, the greater the freeze fraction will be as well. It is noted that while there are not a large number of melt-dominated icing test points to show on Fig. 11, an inflection of the freeze-dominated points around $-0.5{ }^{\circ} \mathrm{C}$ is expected. The same reasoning mentioned for the freeze-dominated trend applies to the melt-dominated regime. As $T w b_{0}$ increases, the melt fraction will increase as ice will more readily melt at warmer conditions. Similarly, due to the nature of many parameters being coupled in this icing tunnel, namely $\eta_{M R}$ and $T w b_{0}$, a warmer environment will be coupled with a higher $\eta_{M R}$ value, and with less ice to melt, the greater the melt fraction value will be.

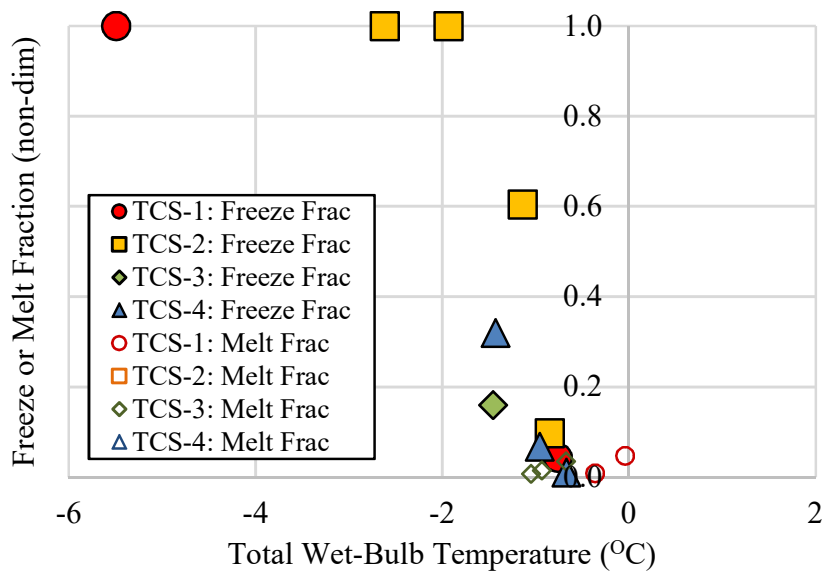

Figure 11. Freeze fraction or melt fraction as determined from the model, plotted against total wet-bulb temperature.

\section{Mass Loss Fraction Analysis}

Running the thermodynamic model to determine the values of $n_{\text {loss }}$, and $n_{0}$ or $m_{0}$, also allowed for the determination of what fraction of the impinging ice is lost due to splash and runback and what fraction is lost by bounce and erosion. Figure 12 shows loss fractions plotted against melt ratio. The large, solid symbols represent the total mass fraction lost as defined by Eq. (15). This again is simply the fraction of the impinging mass flux that did not stick. The smaller empty symbols represent the fraction of the impinging mass flux that did not stick due to splash and runback. These values are determined by Eq. (20) if the icing event was freeze-dominated, and by Eq. (21) if the icing event was melt-dominated. The difference between $F_{\text {loss,total }}$ and $F_{\text {loss }, s p l / r b}$ represents the fraction that was lost due to bounce and erosion. It can be seen in Fig. 12 that $F_{l o s s, s p l / r b}$ increases with increasing $\eta_{M R}$. This is generally intuitive as there is more liquid to be lost at higher $\eta_{M R}$ values. With only small variations in the trend, Fig. 12 suggests that $\eta_{M R}$ is the most domininat factor is determining $F_{l o s s, s p l / r b}$ as compared to any effects that $U$ and $p_{0}$ contribute. The $F_{l o s s, s p l / r b}$ values for the highest velocity case (green empty diamond) is consistently slightly greater than the other cases and may play as a second-order factor in determining the fraction lost due to splash and runback. This is intuitive as higher velocities contribute more to the kinetic energy flux, which promotes more melt.

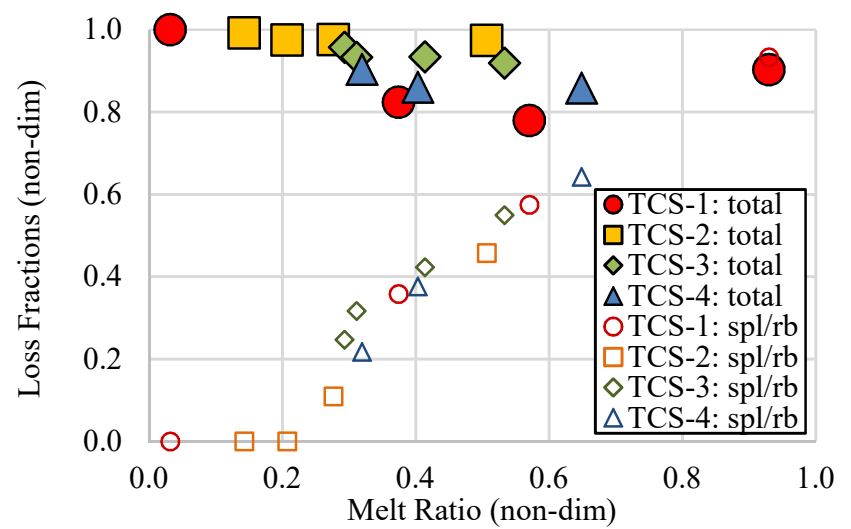

Figure 12. Total mass loss fraction and mass loss fraction due to splash and runback, plotted against melt ratio.

It should be noted that the overlap between the two loss fractions for the highest $\eta_{M R}$ case (TCS-1.D) suggests that there is not enough ice in the impinging ice to create the amount of ice growth measured. This suggests either some supercooling liquid water accretion occurred, or that the measurement and subsequent calculation of $\eta_{M R}$ was too high. For example the points would be equal in loss fraction if $\eta_{M R}$ was calculated to be 0.90 instead of $\eta_{M R}=0.93$.

\section{Icing Surface Equilibrium Temperature Analysis}

A subroutine was added to the thermodynamic ice crystal icing model to determine the icing surface equilibrium temperature, $T_{\text {surf }}$. The icing surface temperature is calculated to be $0{ }^{\circ} \mathrm{C}$ when the freeze fraction or melt fraction equals a value less than unity (if $m_{0}=1$, there is no icing as all ice has melted). If $n_{0}=1$, conditions are sufficiently cold to affect the sensible heat at the accretion surface. The expressions derived in the Icing Surface Equilibrium Temperature Derivation section are used to find $T_{\text {surf }}$. For this exercise, $T_{\text {surf }}$ was calculated at $60 \mathrm{~s}, 240 \mathrm{~s}$, and $600 \mathrm{~s}$ for all possible cases. These calculated values are compared to corresponding airfoil leading edge thermocouple 
temperature data, $T_{T / C}$ and are shown in Table 4. An important distinction to note is that $T_{\text {surf }}$ is a calculated value at the leading edge of the icing surface, while $T_{T / C}$ is a measured value located at the leading edge of the airfoil. These two temperatures are more closely related when the ice thickness at the leading edge is small. Therefore, the comparisons are less likely to agree later in an icing test when the ice accretion is large. The comparisons, however, are still made at these later times to illustrate some points.

Table 4. Comparison of calculated icing surface temperature (model) with experimentally measured thermocouple temperature data (exp.) at $60 \mathrm{~s}, 240 \mathrm{~s}$, and $600 \mathrm{~s}$, for all applicable test cases.

\begin{tabular}{|c|c|c|c|c|c|c|}
\hline Case & $\begin{array}{c}T_{T / C}, \\
(\text { exp.) } \\
60 \mathrm{~s} \\
\left({ }^{\circ} \mathrm{C}\right)\end{array}$ & $\begin{array}{c}T_{\text {surf }} \\
\text { (model) } \\
60 \mathrm{~s} \\
\left({ }^{\circ} \mathrm{C}\right)\end{array}$ & $\begin{array}{c}T_{T / C}, \\
\text { (exp.) } \\
240 \mathrm{~s} \\
\left({ }^{\circ} \mathrm{C}\right) \\
\end{array}$ & $\begin{array}{c}T_{\text {surf }}, \\
\text { (model) } \\
240 \mathrm{~s} \\
\left({ }^{\circ} \mathrm{C}\right)\end{array}$ & $\begin{array}{c}T_{T / C}, \\
\text { (exp.) } \\
600 \mathrm{~s} \\
\left({ }^{\circ} \mathrm{C}\right)\end{array}$ & $\begin{array}{c}\begin{array}{c}T_{\text {surf }}, \\
\text { (model) }\end{array} \\
600 \mathrm{~s} \\
\left({ }^{\circ} \mathrm{C}\right)\end{array}$ \\
\hline \multicolumn{7}{|c|}{ Test Condition Series 1} \\
\hline $\mathrm{A}$ & -4.0 & -5.1 & -4.8 & -5.1 & N/A & N/A \\
\hline $\mathrm{B}$ & 0.0 & 0.0 & 0.0 & 0.0 & 0.0 & 0.0 \\
\hline $\mathrm{C}$ & 0.0 & 0.0 & 0.0 & 0.0 & 0.0 & 0.0 \\
\hline $\mathrm{D}$ & 0.0 & 0.0 & 0.0 & 0.0 & 0.0 & 0.0 \\
\hline \multicolumn{7}{|c|}{ Test Condition Series 2} \\
\hline $\mathrm{A}$ & -0.5 & -2.5 & -0.6 & -2.5 & -0.6 & -2.5 \\
\hline $\mathrm{B}$ & 0.0 & -1.8 & -0.2 & -1.7 & -1.1 & -1.7 \\
\hline $\mathrm{C}$ & 0.0 & 0.0 & 0.0 & 0.0 & -0.1 & 0.0 \\
\hline $\mathrm{D}$ & 0.0 & 0.0 & 0.0 & 0.0 & 0.0 & 0.0 \\
\hline \multicolumn{7}{|c|}{ Test Condition Series 3} \\
\hline $\mathrm{A}$ & 0.0 & -1.2 & -0.1 & 0.0 & -2.3 & 0.0 \\
\hline $\mathrm{B}$ & 0.0 & -0.8 & -0.7 & 0.0 & -2.7 & 0.0 \\
\hline $\mathrm{C}$ & 0.0 & -0.7 & -0.8 & 0.0 & -2.7 & 0.0 \\
\hline $\mathrm{D}$ & 0.0 & 0.0 & -0.5 & 0.0 & -1.9 & 0.0 \\
\hline \multicolumn{7}{|c|}{ Test Condition Series 4} \\
\hline $\mathrm{A}$ & 0.0 & -1.8 & -0.2 & 0.0 & -1.6 & 0.0 \\
\hline $\mathrm{B}$ & 0.0 & -1.3 & 0.0 & 0.0 & -0.4 & 0.0 \\
\hline $\mathrm{C}$ & 0.0 & 0.0 & 0.0 & 0.0 & -0.1 & 0.0 \\
\hline $\mathrm{D}$ & 0.0 & 0.0 & 0.0 & N/A & 0.0 & $\mathrm{~N} / \mathrm{A}$ \\
\hline
\end{tabular}

The following will assess the predicted temperature with T/C data by stepping through each Test Condition Series. Beginning with TCS-1, only Case A shows calculated and measured sub-freezing temperatures. Even though no ice accreted on the surface, sub-zero values were measured. The airfoil, even if just barely wet from the mostly ice impinging cloud, acted as a wetted surface, and registered values near the total wet-bulb temperature. Indeed, for this case $T_{\text {surf }}$ was calculated to be the total wet-bulb temperature. Cases B through $\mathrm{D}$ for TCS-1 were measured and calculated to be $0{ }^{\circ} \mathrm{C}$ at all times. There is good agreement for the measured and calculated values for this test series. Continuing to TCS-2, the two coldest cases (TCS-2.A and TCS-2.B) show calculated and measured sub-freezing temperatures. There is fair agreement in temperature value for this test series as well. Next is the highest velocity series, TCS-3. Some discrepancies occur in this test series. With respect to calculated model values, the three coldest cases (TCS-3.A through TCS-3.C) show subfreezing temperatures at $60 \mathrm{~s}$. However, as ice growth rate increased from no/slow growth rates to higher growth rates, the addition of particle kinetic energy to the icing surface increased the surface temperature at later times ( $240 \mathrm{~s}$ and $600 \mathrm{~s})$. All four T/C temperatures initially start at $0{ }^{\circ} \mathrm{C}$, but continue to decrease in temperature as time progresses for each test. It is believed that heat is conducted in the metal from the airfoil leading edge to colder metal regions downstream on the airfoil, due to reduced temperature recovery factors aft of the leading edge. At higher velocities, such as is the case with TCS-3, the Page 14 of 17 decrease in temperature recovery in the boundary layer aft of the leading edge is even more significant. It is this reasoning that explains the continuously decreasing leading edge T/C temperature trend. Finally, moving to the TCS-4, sub-freezing temperatures are measured and calculated for the two coldest cases. The temperature trends between prediction and experiment as seen in TCS-4.A and TCS-4.B can be explained similarly as described for the TCS-3 series.

Evidence is provided for the hypothesis that heat conducting from the leading edge to colder regions on the metal airfoil contributed to reduced leading edge thermocouple readings later into the test. Thermocouples located downstream of the leading edge at the airfoil midspan corroborate this hypothesis. Figure 13 shows the location of the leading edge thermocouple (T/C 03) and the location of the next closest thermocouple aft of the leading edge (T/C_06). The location of $\mathrm{T} / \mathrm{C} \_06$ is in a region where the temperature recovery factor in the boundary layer is expected to be less than unity. In general, the recovery factor is expected to be approximately $\operatorname{Pr}^{1 / 2}$ for laminar flow and $\operatorname{Pr}^{1 / 3}$ for turbulent flow [25], where $P r$ is the Prandtl number $(P r=$ 0.71 for air). Figure 14 illustrates this reduced temperature downstream of the airfoil leading edge. Figure 14 recreates the ice thickness, leading edge angle, and thermocouple data of TCS-4.A, but also includes the downstream thermocouple reading (T/C_06) along with the leading edge thermocouple reading (T/C_03). Fig. 14 shows that $\mathrm{T} / \mathrm{C} 06$ reads colder than T/C 03 shortly after the activation of the cloud and. This lower temperature will tend to eventually conduct heat away from leading edge of the airfoil, and in this example reducing the leading edge to sub-freezing temperatures.

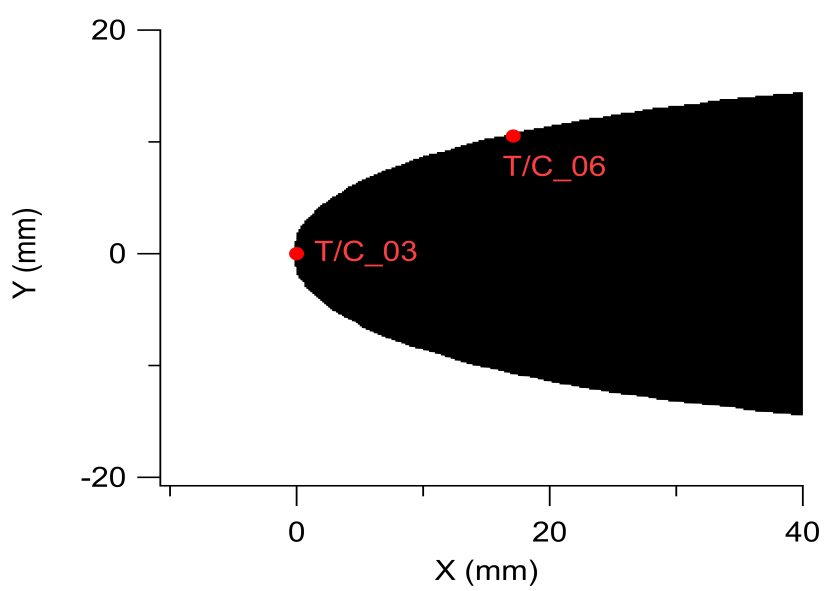

Figure 13. Locations of the leading edge thermocouple and the next closest thermocouple aft of the leading edge of the NACA 0012 airfoil.

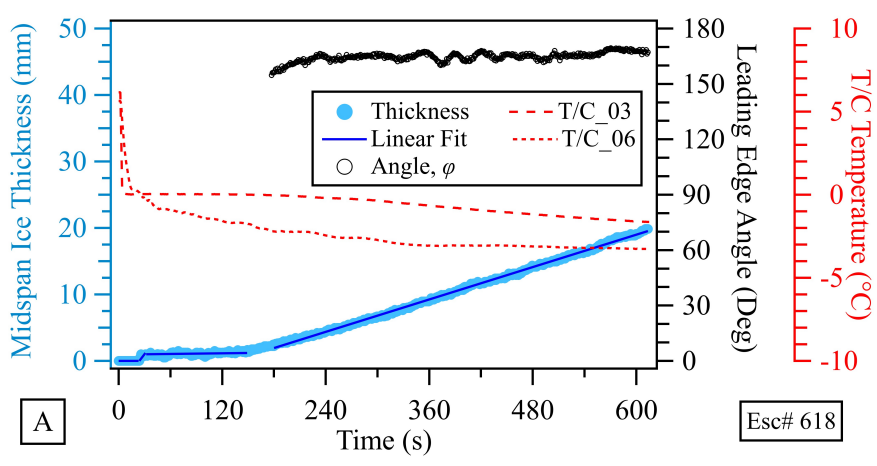

Figure 14. Recreation of the ice thickness, leading edge angle, and thermocouple data of TCS-4.A, but also shows airfoil thermocouple readings downstream of the leading edge, T/C_06 along with the leading edge thermocouple reading, $\mathrm{T} / \mathrm{C} \_03$. 


\section{Discussion}

There are many important points to discuss regarding the results of this paper. The first is the explanation for the time dependent ice growth rates that were observed and measured for the majority of the tests. Most tests underwent a no/slow ice growth period for the first several minutes of the test. It was observed that ice accretion, downstream of the leading edge grew forward toward the leading edge plane. This second front created a larger leading edge surface, which led to a greater leading edge ice growth rate, and subsequently a higher sticking efficiency. For some tests, the leading edge thermocouple, after reaching a freezing temperature, began to slowly decrease to sub-zero temperatures. It is hypothesized that the conduction of heat from the airfoil leading edge to colder regions on the metal airfoil, which is colder due to a reduced temperature recovery factor, contributed to the decreasing thermocouple reading. In addition, it is likely that this local colder region downstream of the airfoil leading edge aided in accreting ice in this region, which allowed for the downstream ice to grow forward towards the leading edge plane. These are phenomena that the thermodynamic model does not capture since it focuses on the leading edge. These comprehensive explanations, however, are necessary to understand the changing ice growth rates that were observed that are ultimately used in the model.

In ice crystal icing, there is a general acceptance that a minimum and maximum melt ratio exists for accretion to occur. The minimum limit is described as the limit below which too little melt occurs preventing the ice from sticking, and the ice crystals simply bounce off the surface without accreting. The maximum limit is described as the limit above which there is too much melt and the impinging ice and water mixture washes away without accreting. Currie $[8,9]$ suggests that in between these limits there exists a plateau region where aggressive growth is possible. The sticking efficiency data as seen in Fig. 10c supports the existence of a minimum melt ratio limit and plateau region. However, the maximum melt ratio limit was not reached for these tests. The maximum melt ratio limit requires that the liquid water does not supercool. In the present experiments it is possible that a portion of the liquid water was supercooling. The $\eta_{M R}$ range of the plateau as measured in this paper ( $\sim 0.3$ to 0.65$)$ exceeds Currie's $[8,9]$ melt ratio range $(\sim 0.10$ to 0.25$)$, and is more in line with the $\eta_{M R}$ range that Baumert [12] reported ( $\sim .2$ to 0.6$)$. It should be noted, however, that $\eta_{M R}$ values reported in this paper are corrected for several uncertainties $[2,3]$, and are calculated differently than by Currie $[8,9]$ and by Baumert [12]. Also, Baumert likely saw supercooled icing with $\eta_{M R}$ values at or near unity, similar to what was likely observed in this work. The height of the icing plateau in this paper was measured to be lower $\left(\eta_{\text {stick }}=0.2\right)$ than both Currie $\left(\eta_{\text {stick }}=0.3\right.$ to 0.5$)$ and Baumert $\left(\eta_{\text {stick }}=0.3\right.$ to 0.4$)$. Different airfoil geometries are likely responsible for part of this difference. In addition, while the $\eta_{\text {stick }}$ values reported by Baumert also used a NACA 0012 airfoil (about twice the chord as the NACA 0012 used in this paper), Baumert's air flow velocity $(40 \mathrm{~m} / \mathrm{s})$ was significantly lower than what was utilized in this testing $(84 \mathrm{~m} / \mathrm{s}, 133 \mathrm{~m} / \mathrm{s}$ and $182 \mathrm{~m} / \mathrm{s})$. Part of the discrepancy in $\eta_{\text {stick }}$ value can be attributed with the finding in this paper that the value of $\eta_{\text {stick }}$ increases with decreasing velocity. This correlation between velocity and sticking efficiency is "possibly" in agreement with Currie [9]. The finding that total pressure has little effect on $\eta_{\text {stick }}$ is in agreement with the work by both Currie and Baumert.

This work examined leading edge ice accretion, and many of the findings associated with $\varphi$ are in agreement with Baumert et al. [12]. These findings include that a decrease in $\varphi$ is accompanied by a decrease in ice growth rate, and therefore a lower $\eta_{\text {stick }}$ value. In addition, as $\eta_{M R}$ decreased, $\varphi$ decreased as well, likely due to erosion that occurred with a greater fraction of impinging particles being glaciated at lower $\eta_{M R}$ values. The accretion angle plays an important role in ice growth. As reported by Currie [9], most tests reached a steady-state ice size, except where the $\eta_{\text {stick }}$ value remained non-zero for all oblique impingement angles, in which case the ice grew indefinitely. All ice accretions grew without reaching a size limit during the $\sim 600 \mathrm{~s}$ test runs reported in this paper (aided by the secondary icing front). This indefinite ice growth is in agreement with Baumert.

\section{Summary/Conclusions}

There were several key findings in this paper. First, the thermodynamic ice crystal icing model showed that $T w b_{0}$ is a good predictor for determining the type of icing that will accrete. To the first order, freeze-dominated icing occurs for sub-freezing $T w b_{0}$ values, while melt-dominated icing occurs for $T w b_{0}$ above $0{ }^{\circ} \mathrm{C}$ values. The kinetic energy surface flux provides additional energy to the icing surface, which slightly shifts the melt-dominated regime to small sub-freezing $T w b_{0}$ values. The greater the kinetic energy flux (i.e. higher velocity), the greater the shift into the sub-freezing $T w b_{0}$ domain. Also, the lower the $T w b_{0}$, the greater the fraction of liquid water that will freeze. If sufficiently cold, the freeze fraction reaches $n_{0}=1$ and the icing surface temperature can shift from mixed phase temperatures of $0{ }^{\circ} \mathrm{C}$ to fully glaciated sub-freezing temperatures. Additions to the model predicted this sensible energy change. The predicted icing surface temperatures were in good agreement with experimental temperature values that were measured with a thermocouple located at the airfoil leading edge. Some disagreement in temperatures were observed late in testing for some test cases. Colder regions downstream of the leading edge, due to a reduced temperature recovery factor, likely conducted heat away from the airfoil leading edge, producing sub-freezing thermocouple readings late into some tests. This colder region downstream of the leading edge aided initial ice growth in the local cold region, which grew forward towards the leading edge. This secondary front then supported further ice growth at the leading edge. This dynamic helps explain the observed time-dependent leading edge ice accretion rates. These two-dimensional dynamics point out the shortcomings of the thermodynamic model, as it focuses on the stagnation point, however the model did aid in understanding complex icing dynamics.

This paper calculated sticking efficiency, and supports the existence of a minimum melt ratio limit and plateau region. However, the maximum melt ratio limit was not reached for the conditions run. The plateau region range from $\eta_{M R} \sim 0.3$ to 0.65 , and perhaps even to higher melt ratio values. This $\eta_{M R}$ range is in agreement with Baumert [12] and extends wider than Currie $[8,9]$. The plateau region reached a $\eta_{\text {stick }}$ value of 0.2 , which was lower than other reported $\eta_{\text {stick }}$ values. This difference can in part be explained by the higher velocities that were run, which this paper showed that the plateau became shallower at higher velocities. The higher velocities also pushed the accretion range further towards higher $\eta_{M R}$ values, likely because higher velocities resulted in greater erosion for more glaciated clouds.

Finally, the ice accretion leading edge angle was investigated for the icing tests. A key finding is that an increase in $\varphi$ is accompanied by an increase in ice growth rate, and therefore a higher $\eta_{\text {stick }}$ value. This angle played in important role when downstream ice grew forward toward the leading edge, which increased $\varphi$, which ultimately increased the leading edge growth rate. In addition, as $\eta_{M R}$ decreased, $\varphi$ decreased as well, likely due to the higher erosion that occurred at lower $\eta_{M R}$ values. These ice accretion angle findings are in agreement with Baumert [12]. 


\section{References}

1. Mason, J. G., Strapp, J. W., and Chow, P., "The Ice Particle Threat to Engines in Flight," 44th AIAA Aerospace Sciences Meeting and Exhibit, AIAA, Reno, NV, 2006, doi: 10.2514/6.2006-206.

2. Struk, P. M., Ratvasky, T. P., Bencic, T., Van Zante, J. F., King, M. C., Tsao, J.-C., and Bartkus, T. P., "An Initial Study of the Fundamentals of Ice Crystal Icing Physics in the NASA Propulsion Systems Laboratory," 9th AIAA Atmospheric and Space Environments Conference, AIAA, Denver, CO, 2017, doi: 10.2514/6.2017-4242.

3. Struk, P., Agui, J., Bartkus, T., and Tsao, J-C., "Ice-crystal icing accretion studies at the NASA Propulsion Systems Laboratory," SAE 2019 International Conference on Icing of Aircraft, Engines, and Structures, SAE International, Minneapolis, MN, 2019 (submitted for publication).

4. Struk, P. M., King, M. C., Bartkus, T. P., Tsao, J-C., Fuleki, D., Neuteboom, M., and Chalmers, J. L., "Ice Crystal Icing Physics Study Using a NACA 0012 Airfoil at the National Research Council of Canada's Research Altitude Test Facility," 2018 AIAA Atmospheric and Space Environments Conference, AIAA, Atlanta, GA, 2018, doi:10.2514/6.2018-4224.

5. Struk, P. M., Bartkus, T. P., Tsao, J. C., Currie, T., and Fuleki, D., "Ice Accretion Measurements on an Airfoil and Wedge in Mixed-Phase Conditions," SAE 2015 International Conference on Icing of Aircraft, Engines, and Structures, SAE International, Prague, CZ, 2015, doi: 10.4271/2015-01-2116.

6. Struk, P. M., Broeren, A. P., Tsao, J-C., Vargas, M., Wright, W. B., Currie, T., Knezevici, D., and Fuleki, D., "Fundamental Ice Crystal Accretion Physics Studies," SAE 2011 International Conference on Aircraft and Engine Icing and Ground Deicing, NASA/TM-2012-217429, 2011, doi: 10.4271/2011-38-0018.

7. Currie, T. C., Struk, P. M., Tsao, J., Fuleki, D., and Knezevici, D. C. "Fundamental Study of Mixed-Phase Icing with Application to Ice Crystal Accretion in Aircraft Jet Engines," 4th Atmospheric and Space Environments Conference, AIAA, New Orleans, LA, 2012, doi: 10.2514/6.2012-3035.

8. Currie, T. C., Fuleki, D., Knezevici, D. C., and MacLeod, J. D. "Altitude Scaling of Ice Crystal Accretion," 5th AIAA Atmospheric and Space Environments Conference, AIAA, San Diego, CA, 2013, doi: 10.2514/6.2013-2677.

9. Currie, T. C., Fuleki, D., and Mahallati, A. "Experimental Studies of Mixed-Phase Sticking Efficiency for Ice Crystal Accretion in Jet Engines," 6th AIAA Atmospheric and Space Environments Conference, AIAA, Atlanta, GA, 2014, doi: 10.2514/6.2014-3049.

10. Knezevici, D. C., Fuleki, D., Currie, T. C., Galeote, B., Chalmers, J., and MacLeod, J. D. "Particle Size Effects on Ice Crystal Accretion - Part II," 5th AIAA Atmospheric and Space Environments Conference, AIAA, San Diego, CA, 2013, doi: 10.2514/6.2013-2676.

11. Knezevici, D. C., Fuleki, D., Currie, T. C., and MacLeod, J. D. "Particle Size Effects on Ice Crystal Accretion," 4th AIAA Atmospheric and Space Environments Conference, AIAA, New Orleans, LA, 2012, doi: 10.2514/6.2012-3039.

12. Baumert, A., Bansmer, S., Trontin, P., and Villedieu, P., "Experimental and numerical investigation on aircraft icing at mixed phase conditions," International Journal of Heat and Mass Transfer 123: 957-978, 2018, doi: 10.1016/j.ijheatmasstransfer.2018.02.008.

13. Currie, T., Fuleki, D., and Davison, C., "Simulation of Ice Particle Melting in the NRCC RATFac Mixed-Phase Icing Tunnel," SAE 2015 International Conference on Icing of Aircraft, Engines, and
Structures, SAE International, Prague, CZ, 2015, doi: 10.4271/2015-01-2107.

14. Trontin, P., Knotagiannis, A., Blanchard, G., and Villedieu, P., "Description and assessment of the new ONERA 2D icing suite IGLOO2D.," 9th AIAA Atmospheric and Space Environments Conference, AIAA, Denver, CO, 2017, doi: 10.2514/6.20173417.

15. Messinger, B. L., "Equilibrium Temperature of an Unheated Icing Surface as a Function of Air Speed," Journal of Aeronautical Science 20: 29-42, 1953, doi: 10.2514/8.2520.

16. Tsao, J-C., Struk, P. M., and Oliver, M. J., "Possible Mechanisms for Turbofan Engine Ice Crystal Icing at High Altitude," 6th AIAA Atmospheric and Space Environments Conference, AIAA, Atlanta, GA, 2014, doi: 10.2514/6.2014-3044.

17. Bartkus, T. P., Struk, P. M., and Tsao, J-C., "Evaluation of a Thermodynamic Ice Crystal Icing Model Using Experimental Ice Accretion Data", 2018 AIAA Atmospheric and Space Environments Conference, AIAA, Atlanta, GA, 2018, doi: 10.2514/6.2018-4129.

18. Rigby, D. L., Struk, P. M., and Bidwell, C. S., "Simulation of Fluid Flow and Collection Efficiency for an SEA Multi-Element Probe," 6th AIAA Atmospheric and Space Environments Conference, AIAA, Atlanta, GA, 2014, doi: 10.2514/6.2014 2752.

19. Bartkus, T. P., Struk, P. M., and Tsao, J-C., "Comparisons of Mixed-Phase Icing Cloud Simulations with Experiments Conducted at the NASA Propulsion Systems Laboratory," 9th AIAA Atmospheric and Space Environments Conference, AIAA, Denver, CO, 2017, doi: 10.2514/6.2017-4243.

20. Bartkus, T. P., Struk, P. M., Tsao, J. C., and Van Zante, J. F., "Numerical Analysis of Mixed-Phase Icing Cloud Simulations in the NASA Propulsion Systems Laboratory," 8th AIAA Atmospheric and Space Environments Conference, AIAA, Washington D.C., 2016, doi: 10.2514/6.2016-3739.

21. Bartkus, T. P., Struk, P. M., and Tsao, J. C., "Development of a Coupled Air and Particle Thermal Model for Engine Icing Test Facilities," SAE International Journal of Aerospace, Vol. 8, No. 1, 2015, pp. 15-32, doi: 10.4271/2015-01-2155.

22. Agui, J. H., Struk, P. M., and Bartkus, T. P., "Total Temperature Measurements Using a Rearward Facing Probe in Supercooled Liquid Droplet and Ice Crystal Clouds," 2018 AIAA Atmospheric and Space Environments Conference, AIAA, Atlanta, GA, 2018, doi:10.2514/6.2018-3970.

23. Agui, J., Struk, P., and Bartkus, T., "Total Temperature Measurements in Icing Cloud Flows using a Rearward Facing Prove," SAE 2019 International Conference on Icing of Aircraft, Engines, and Structures, SAE International, Minneapolis, MN, 2019 (submitted for publication).

24. King, M. C., Manin, J., Van Zante, J. F., Timko, E. N., and Struk, P. M., "Particle Size Calibration Testing in the NASA Propulsion System Laboratory," 2018 AIAA Atmospheric and Space Environments Conference, AIAA, Atlanta, GA, 2018, doi: 10.2514/6.2018-3971.

25. Schlichting, H., "Boundary-Layer Theory, Seventh Edition," (New York, McGraw-Hill, 1979), pg. 335, 714, doi: 10.1002/zamm.19800600419.

\section{Contact Information}

Tadas P. Bartkus, Ph.D.

Work phone: (216) 433-6915

E-mail: tadas.p.bartkus@nasa.gov

Affiliation: Ohio Aerospace Institute

Page 16 of 17 


\section{Acknowledgments}

The authors wish to acknowledge the Advanced Aircraft Icing (AAI) sub-project of the NASA Advanced Air Transport Technology Project (AATT), under NASA's Advanced Air Vehicles Program (AAVP), for financial support for this work.

\section{Nomenclature}

$\boldsymbol{C p} \quad$ specific heat capacity $(\mathrm{J} / \mathrm{kg} / \mathrm{K})$

$\boldsymbol{F}_{\text {loss,total }}$ fraction of impinging mass flux that does not accrete (dimensionless)

$\boldsymbol{F}_{\text {loss,spl/rb }}$ fraction of impinging mass flux that does not accrete due to splash and runback (dimensionless)

$\boldsymbol{h}_{\boldsymbol{c}} \quad$ convective heat transfer coefficient $\left(\mathrm{W} / \mathrm{m}^{2} / \mathrm{K}\right)$

$\boldsymbol{h}_{\boldsymbol{m}} \quad$ mass transfer coefficient $\left(\mathrm{kg} / \mathrm{m}^{2} / \mathrm{s}\right)$

$\boldsymbol{j} \quad$ positive integers in the summation of the heat equation infinite series solution (dimensionless)

$\boldsymbol{k}$ thermal conductivity $(\mathrm{W} / \mathrm{m} / \mathrm{K})$

$\boldsymbol{L} \quad$ thickness of airfoil shell (m)

$\boldsymbol{L}_{\boldsymbol{f}} \quad$ latent heat of fusion (freezing or melting) $(\mathrm{J} / \mathrm{g})$

$\boldsymbol{L}_{\boldsymbol{v}} \quad$ latent heat of vaporization $(\mathrm{J} / \mathrm{g})$

$\boldsymbol{\eta}_{\boldsymbol{M} \boldsymbol{R}}$ melt ratio, ratio of liquid water content to total of liquid + ice water content (dimensionless)

MVD median volumetric diameter, in reference to the particle size spray distribution (microns)

$\boldsymbol{m}_{\mathbf{0}} \quad$ surface melting fraction of ice water at stagnation (dimensionless)

$\dot{\boldsymbol{m}}_{\boldsymbol{e}} \quad$ evaporative mass flux $\left(\mathrm{kg} / \mathrm{m}^{2} / \mathrm{s}\right)$

$\dot{\boldsymbol{m}}_{\boldsymbol{i m p} \text {,ice }}^{\prime \prime}$ mass flux of impinging solid ice water $\left(\mathrm{kg} / \mathrm{m}^{2} / \mathrm{s}\right)$

$\dot{\boldsymbol{m}}_{\boldsymbol{i m p}, \boldsymbol{l i q}}^{\prime \prime}$ mass flux of impinging liquid water time $\left(\mathrm{kg} / \mathrm{m}^{2} / \mathrm{s}\right)$

$\dot{\boldsymbol{m}}_{\boldsymbol{i m p}, \boldsymbol{t o t a l}}^{\prime \prime}$ total impinging water mass flux (ice and liquid) $\left(\mathrm{kg} / \mathrm{m}^{2} / \mathrm{s}\right)$

no surface freezing fraction of liquid water at stagnation (dimensionless)

$\boldsymbol{n}_{\text {loss }}$ fractional mass loss of ice due to bounce and erosion (dimensionless)

$\widehat{\boldsymbol{n}} \quad$ in the normal direction; distance into the airfoil leading edge wall, in the tunnel axial direction (m)

p pressure $(\mathrm{Pa})$

$\boldsymbol{p}_{\boldsymbol{v}, \boldsymbol{s}} \quad$ saturation vapor pressure of water in atmosphere, at static temperature $(\mathrm{Pa})$

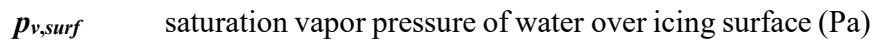

Pr Prandtl number (dimensionless)

$\boldsymbol{q}_{\text {cond }}^{\prime \prime} \quad$ conductive heat transfer surface flux $\left(\mathrm{W} / \mathrm{m}^{2}\right)$

$\bar{q}_{\text {cond }}$

$q_{\text {conv }}^{\prime \prime}$

$q_{\text {evap }}^{\prime \prime}$

$q_{\text {freeze }}^{\prime \prime}$

$q_{\text {kinetic }}^{\prime \prime}$

$q_{\text {melt }}^{\prime \prime}$

$q_{\text {sens,ice }}^{\prime \prime}$ conductive heat transfer surface flux, averaged over a period of time $\left(\mathrm{W} / \mathrm{m}^{2}\right)$

convective heat transfer surface flux $\left(\mathrm{W} / \mathrm{m}^{2}\right)$

evaporative heat transfer surface flux $\left(\mathrm{W} / \mathrm{m}^{2}\right)$

latent heat of fusion surface energy for freeze-dominated icing $\left(\mathrm{W} / \mathrm{m}^{2}\right)$

kinetic energy surface flux $\left(\mathrm{W} / \mathrm{m}^{2}\right)$

latent heat of fusion surface energy for melt-dominated icing $\left(\mathrm{W} / \mathrm{m}^{2}\right)$

sensible heat surface flux for frozen ice $\left(\mathrm{W} / \mathrm{m}^{2}\right)$ $\beta_{0} \quad$ collection efficiency at the stagnation line (dimensionless)
$\boldsymbol{\eta}_{\text {stick }}$ fraction of impinging mass flux retained (sticks) on the surface (dimensionless)
$\rho \quad$ density
$\boldsymbol{\varphi} \quad$ leading edge ice accretion angle

$\begin{array}{ll}\text { Subscripts } \\ \boldsymbol{O} & \text { total conditions } \\ \boldsymbol{i} & \text { initial state } \\ \boldsymbol{i c e} & \text { ice } \\ \boldsymbol{P L} & \text { plenum of tunnel } \\ \boldsymbol{S} & \text { static conditions } \\ \text { surf } & \text { icing surface } \\ \text { targ } & \text { target } \\ \text { wall } & \text { wall, airfoil surface }\end{array}$

\section{Abbreviations}

Esc

Escort number

NASA

National Aeronautics and Space Administration

PSL

Propulsion Systems Laboratory

TCS

Test Condition Series

$\mathbf{T} / \mathrm{C}$

Thermocouple

T/C_03

Thermocouple at leading edge

T/C_06

Thermocouple just aft of leading edge 